\title{
Triggering Receptor Expressed on Myeloid Cells 2 (TREM2) Deficiency Attenuates Phagocytic Activities of Microglia and Exacerbates Ischemic Damage in Experimental Stroke
}

\author{
Masahito Kawabori, ${ }^{1}$ Rachid Kacimi, ${ }^{1,2}$ Tiina Kauppinen, ${ }^{3}$ Cyrus Calosing, ${ }^{1}$ Jong Youl Kim, ${ }^{1}$ Christine L. Hsieh, ${ }^{1,2}$ \\ Mary C. Nakamura, ${ }^{1}$ and $\odot$ Midori A. Yenari ${ }^{1,2}$ \\ ${ }^{1}$ Departments of Neurology and Medicine, University of California, San Francisco, and ${ }^{2}$ San Francisco Veterans Affairs Medical Center, San Francisco, \\ California 94121, and ${ }^{3}$ Kleysen Institute for Advanced Medicine, Winnipeg, Manitoba R3E 0Z3, Canada
}

\begin{abstract}
Clearing cellular debris after brain injury represents an important mechanism in regaining tissue homeostasis and promoting functional recovery. Triggering receptor expressed on myeloid cells-2 (TREM2) is a newly identified receptor expressed on microglia and is thought to phagocytose damaged brain cells. The precise role of TREM2 during ischemic stroke has not been fully understood. We explore TREM2 in both in vitro and in vivo stroke models and identify a potential endogenous TREM2 ligand. TREM 2 knockdown in microglia reduced microglial activation to an amoeboid phenotype and decreased the phagocytosis of injured neurons. Phagocytosis and infarcted brain tissue resorption was reduced in TREM2 knock-out (KO) mice compared with wild-type (WT) mice. TREM2 K0 mice also had worsened neurological recovery and decreased viable brain tissue in the ipsilateral hemisphere. The numbers of activated microglia and phagocytes in TREM2 KO mice were decreased compared with WT mice, and foamy macrophages were nearly absent in the TREM2 K0 mice. Postischemia, TREM2 was highly expressed on microglia and TREM2-Fc fusion protein (used as a probe to identify potential TREM2 binding partners) bound to an unknown TREM2 ligand that colocalized to neurons. Oxygen glucose deprivation-exposed neuronal media, or cellular fractions containing nuclei or purified DNA, but not cytosolic fractions, stimulated signaling through TREM2. TREM2-Fc fusion protein pulled down nucleic acids from ischemic brain lysate. These findings establish the relevance of TREM2 in the phagocytosis of the infarcted brain and emphasize its role in influencing neurological outcomes following stroke. Further, nucleic acids may be one potential ligand of TREM 2 in brain ischemia.
\end{abstract}

Key words: ischemia; neuroprotection; permanent ischemia; phagocytosis; stroke; triggering receptor expressed on myeloid cells-2

\section{Introduction}

Microglia represent the first line of defense against brain injury, such as stroke, and are rapidly mobilized to the site of injury. They not only initiate effector molecules and the recruitment of other immune cells, but also act as a scavenger for damaged cells (Schilling et al., 2005). In recent years, numerous studies (Yenari et al., 2010; del Zoppo et al., 2012) have addressed the microglial functions of chemotaxis, and the secretion of proinflammatory

\footnotetext{
Received June 24, 2014; revised Nov. 19, 2014; accepted Dec. 22, 2014.

Author contributions: M.K., C.L.H., M.C.N., and M.A.Y. designed research; M.K., R.K., T.K., C.C., and J.Y.K. performed research; M.K., C.C., and M.A.Y. analyzed data; M.K. and M.A.Y. wrote the paper.

This work was supported by National Institutes of Health Grants NS40516 to M.A.Y. and AR0038 to M.C.N.; Veteran's Merit Awards to M.A.Y. and M.C.N.; a Uehara Foundation Research Fellowship to M.K.; a Department of Veterans Affairs, Veterans Health Administration, Office of Research and Development, Biomedical Laboratory Research and Development Career Development Award-2 to C.L.H.; and American Heart Association Grant 0835222N to T.K. Grants to M.A.Y., M.C.N., and T.K. were administered by the Northern California Institute for Research and Education, and supported by resources of the Veterans Affairs Medical Center, San Francisco, California. M.C.N. also received support from the Rosalind Russell Arthritis Center. The authors thank Dr. Nick Cairns for labeling the TREM2 fusion protein.

The authors declare no competing financial interests.

Correspondence should be addressed to Midori A. Yenari, Department of Neurology, University of California, San Francisco and SF VAMC, 4150 Clement Street, MS 127, San Francisco, CA 94121. E-mail: yenari@alum.mit.edu. DOI:10.1523/JNEUROSCI.2620-14.2015

Copyright $\odot 2015$ the authors $\quad 0270-6474 / 15 / 353384-13 \$ 15.00 / 0$
}

and anti-inflammatory cytokines, growth factors, chemokines, proteases, and neurotrophins. However, reports of microglial phagocytosis are surprisingly limited. Several microglial phagocytic pathways have been demonstrated to date (Fu et al., 2014), and efficient clearance of tissue debris is thought to be critical in the reconstruction and reorganization of neuronal networking after brain injury. Whether microglial phagocytosis plays a beneficial or detrimental role in brain diseases remains controversial. One newly identified receptor that may be involved in microglial phagocytosis is triggering receptor expressed on myeloid cells- 2 (TREM2), and recent studies have shown that TREM2 is detected exclusively on myeloid cells, including brain microglia. TREM2 was originally described as being involved in the phagocytosis of various pathogens (Daws et al., 2001). TREM2 bound anionic ligands on various bacterial and yeast, but it was also shown to bind an unknown ligand on cultured astrocytomas (Daws et al., 2003).

The importance of TREM2 in the brain has been demonstrated by the findings that a neurodegenerative disease called Nasu-Hakola disease [or polycystic lipomembranous osteodysplasia with sclerosing leukoencephalopathy (PLOSL)] develops in individuals with a loss or mutation in TREM2 or its signaling adapter protein DAP12. This rare disorder causes dementia, sei- 
zures, and death, demonstrating that TREM2 is necessary for the maintenance of brain homeostasis (Numasawa et al., 2011). In addition, mutations in the TREM2 gene have also been linked to Alzheimer's disease (Guerreiro and Hardy, 2013). The role of TREM2 in ischemic brain injury is largely unstudied, and the endogenous ligand for TREM2 in the brain is unknown. We previously showed that TREM2 is upregulated by brain ischemia and is also associated with increased expression on microglia/macrophages under conditions of therapeutic hypothermia (Kawabori et al., 2013b). Here, we explore whether TREM2 is involved in phagocytosis in brain ischemia, and whether TREM2 deficiency worsens the injury following experimental stroke. We also attempt to identify a potential ligand for TREM2 in the ischemic brain.

\section{Materials and Methods}

All experimental procedures were approved by the San Francisco Veterans Affairs Medical Center Institutional Animal Care and Use Committee, and were in accordance with National Institutes of Health guidelines.

\section{Brain cell cultures and oxygen glucose deprivation}

Primary neuron-astrocyte-microglia cultures (NAM) were prepared using previously established methods from our laboratory (Lee et al., 2001; Zheng et al., 2008; Webster et al., 2013). Mixed glial cultures were prepared from C57BL/6 postnatal day 1 (P1) to P3 mouse pups for the following two purposes: to prepare enriched astroglia cultures and to harvest microglia. To prepare enriched astrocytes, mitosis inhibitor (25 $\mu \mathrm{M}$ cytosine $\beta$-D-arabinofuranoside for $48 \mathrm{~h}$ ) was used at $8 \mathrm{~d}$ in vitro (DIV) to eliminate microglia. When astrocytes were 14 DIV, primary neurons were prepared from E16 C57BL/6 mouse embryos and plated on top of astrocytes. When neurons were $8 \mathrm{DIV}$, primary microglia were harvested from mixed glia cultures (that were not treated with mitosis inhibitor and were fed continuously with $10 \%$ sera) by a previously described method (Kauppinen and Swanson, 2005) and plated on top of the neuron-astrocyte (NA) cultures at a density of $1-3 \times 10^{4}$ cells $/ \mathrm{ml}$ or at an approximate microglia/neuron/astrocyte ratio of 1:10:10; and were allowed to stabilize for $24 \mathrm{~h}$. All cells were plated at the same density at the beginning of each experiment, and microglia were counted to ensure consistent densities before plating on top of neurons. In other experiments where large numbers of cells were required, Neuro-2A cells (neuron cell line) and BV2 cells (a murine microglial cell line) were plated at similar densities. All cultures were maintained in a $5 \% \mathrm{CO}_{2}$ chamber.

To simulate ischemic conditions, cultures were exposed to oxygen glucose deprivation (OGD), as previously described (Lee et al., 2001). Cultures were maintained in an anoxic chamber for $1 \mathrm{~h}$ at $37^{\circ} \mathrm{C}$, unless otherwise specified, and oxygen tension was maintained at $<0.001 \%$ (Coy Laboratories). Media were removed, and cultures were washed three times with balanced salt solution lacking serum or glucose, or oxygen (BSS0). Control cultures were incubated under normoxia with balanced salt solution containing $5.5 \mathrm{~mm}$ glucose (BSS5.5). After $1 \mathrm{~h}$ of OGD, glucose was added to each well to a final concentration of $5.5 \mathrm{~mm}$, and plates were incubated at normoxia in a regular incubator for $23 \mathrm{~h}$ at $5 \% \mathrm{CO}_{2}$ at $37^{\circ} \mathrm{C}$ ("reperfusion").

\section{Gene knockdown in microglial cells}

TREM2 gene knockdown was accomplished using a lentiviral vector in primary microglial cells. The mixed glial cultures were transduced with a lentiviral TREM2 RNAi system, as previously described (Hsieh et al., 2009). Briefly, at 10 DIV the cells were incubated with lentiviral TREM2 shRNA (TREM2 shRNA-GFP 3.7; 5'-GAAGCGGAATGGGAGCACA$3^{\prime}$ ) or control empty virus (GFP 3.7) in MEM supplemented with $10 \%$ fetal bovine serum (FBS; HyClone) for $24 \mathrm{~h}$, after which cultures received a complete change of medium. Cultures were allowed to rest another $24 \mathrm{~h}$ before microglia were harvested from these cultures and plated onto NA cultures. NAM cultures were used for experiments $24 \mathrm{~h}$ later. Gene knockdown was also performed in BV2 cells, as previously described (Webster et al., 2013). BV2 cells were cultured in RPMI media [University of California, San Francisco (UCSF) Cell Culture Facility, San Fran- cisco, CA], supplemented with 10\% FBS (Hyclone) and penicillin/ streptomycin. BV2 cells were transfected with TREM2 or control siRNA. In serum-free OptiMEM media (UCSF Cell Culture Facility), Lipofectamine (Invitrogen) reagent was incubated for $15 \mathrm{~min}$ at a concentration of $3.6 \mu \mathrm{l}$ of reagent to $1.5 \mathrm{ml}$ of OptiMEM. Concurrently, PLUS reagent (Invitrogen) $15 \mu \mathrm{l} / 1.5 \mathrm{ml}$ was mixed with the siRNA at a concentration derived from $10.8 \mu \mathrm{l}$ of siRNA (Ambion) from a stock of 50 $\mu \mathrm{M} / 1.5 \mathrm{ml}$ OptiMem or $5.4 \mu \mathrm{l}$ siRNA, when two different targets of the same gene were used. The final concentration of siRNA was $30 \mathrm{~nm}$. The $1.5 \mathrm{ml}$ of OptiMEM containing Lipofectamine was mixed and incubated for $30 \mathrm{~min}$ with the equivalent volume of OptiMEM containing the siRNA and PLUS reagent. BV2 cells were then washed with PBS, trypsinized (0.25\% Trypsin, UCSF Cell Culture Facility), and plated at $1.25 \times 10^{5}$ cells in wells of a six-well plate containing $0.5 \mathrm{ml}$ of the mixture of transfection reagent and siRNAs for reverse transfection. Cells were allowed to freely float in reagent until they adhered to the bottom of the plate. OptiMEM, $0.5 \mathrm{ml}$, was added to each well so that the final concentration of siRNA was $300 \mathrm{~nm}$. The BV2 cells were allowed to incubate in the reagent for $4 \mathrm{~h}$ at $37^{\circ} \mathrm{C}$ in $5 \% \mathrm{CO}_{2}$, then the media were exchanged with antibiotic-free RPMI medium plus 10\% FBS.

\section{Microglial activation and neuronal viability}

The activation status of the microglia was determined based on their morphology, which was assessed by phase contrast microscopy. Microglia with two or more thin processes were considered ramified; and resting microglia and microglia with less than two processes or with amoeboid cell soma, were classified as activated (Kauppinen and Swanson, 2005). The numbers of resting and activated microglia were counted in five randomly selected fields per culture well. Neuronal survival was assessed by counting neuronal somas in five randomly selected phase contrast microscopic fields per culture well (Kauppinen et al., 2011). Values were normalized to counts in control wells (Ctrl-NA) from the same 24-well plate.

\section{Phagocytosis assay}

BV2 microglial cultures were plated on poly-L-lysine-coated 12-well plates and were grown to subconfluence DMEM (Invitrogen) supplemented with $10 \%$ FBS (Hyclone). In parallel, Neuro-2A cells were plated on $25 \mathrm{~cm}^{2}$ tissue culture flasks and were grown in DMEM supplemented with $10 \%$ FBS. All tissue culture medium was supplemented with 100 $\mathrm{U} / \mathrm{ml}$ penicillin $\mathrm{G}$ and $100 \mu \mathrm{g} / \mathrm{ml}$ streptomycin (Invitrogen), as previously described (Kacimi et al., 2011). Cells were left to adhere overnight and then were switched to serum-free media when target cells were added for the phagocytosis assay. To initiate the phagocytosis assay, Neuro-2A cells were first loaded with CM-DiI dye for $30 \mathrm{~min}$, then media were removed. Cells were then washed with PBS to eliminate free dye in the media. Stained Neuro-2A cells were then exposed to $2 \mathrm{~h}$ of OGD followed by $22 \mathrm{~h}$ of reperfusion, as described above. Injured neurons and cellular debris were collected by centrifugation and washed three times with PBS to remove any background fluorescence from the media. Injured Neuro-2A cells were then resuspended in serum-free media and seeded on top of the BV2 cells transfected with either control siRNA or siRNA against TREM2. Cells were incubated for $1 \mathrm{~h}$ at $37^{\circ} \mathrm{C}$ in a $\mathrm{CO}_{2}$ incubator. Thereafter, ice-cold PBS was added to arrest the phagocytosis reaction and neuronal uptake. Cells were washed three times to remove unphagocytosed floating cells and debris. Microglia were examined by fluorescence microscopy. Phagocytosis of neurons was evaluated by the number of DiI (red fluorescent)-positive BV2 cells. Digital images of randomly selected fields were captured, and the number of engulfed cells was counted as a positive index of phagocytosis using a Zeiss Axiovert $40 \mathrm{CFL}$ fluorescence microscope. Phagocytosis of OGD-exposed neurons were compared from BV2 cells with or without intact TREM2.

\section{TREM2 reporter assay}

The BWZ thymoma reporter cell line (a gift from Dr. Nilabh Shastri, University of California, Berkeley, Berkeley, CA), which expresses lacZ under the control of the NFAT promoter, was transfected with lentivirus to coexpress TREM2 and DAP12 (Hsieh et al., 2009). A TREM2/DAP12expressing BWZ cell clone (BWZ/TREM2/DAP12) was used to assay binding and functional triggering of TREM2 signaling. BWZ/TREM2/ 
DAP12 cells or, as a control, parental BWZ cells were plated at $1 \times 10^{6}$ cells $/ \mathrm{ml}$ in 96-well plates. Neuro-2A cells were subjected to OGD for $1 \mathrm{~h}$ followed by $24 \mathrm{~h}$ of reperfusion. Subcellular fractions were obtained by differential centrifugation. Briefly, cells were resuspended in fractionation buffer (250 mm sucrose, $20 \mathrm{~mm}$ HEPES, $10 \mathrm{~mm} \mathrm{KCl}, 1.5 \mathrm{~mm} \mathrm{MgCl} 2$ ) then were lysed by passing through a 25 ga needle 10 times. Lysate was equilibrated on ice for $20 \mathrm{~min}$. Nuclei were pelleted at $720 \times g$ for $5 \mathrm{~min}$. The remaining supernatant was cleared at $10,000 \times g$ for 30 min into mitochondria and cytosol fractions. DNA was also purified from whole Neuro-2A cells using a Qiagen DNeasy kit. Reporter cells were stimulated with $10 \mu \mathrm{l}$ of Neuro-2A conditioned media or subcellular fractions for $16 \mathrm{~h}$ at $37^{\circ} \mathrm{C}$, washed, and lysed in a buffer containing $100 \mathrm{~mm} 2-\mathrm{ME}, 9$ $\mathrm{mM} \mathrm{MgCl}, 0.125 \% \mathrm{NP}-40$, and $30 \mathrm{~mm}$ chlorophenol red galactosidase. Plates were developed at $37^{\circ} \mathrm{C}$, and lacZ activity was measured as previously described (Sanderson and Shastri, 1994).

\section{Animal models}

Male TREM2 knock-out (KO) mice and wild-type (WT) littermates were originally generated by M. Colonna (Washington University, St. Louis, MO), who made them available to us. Mice were backcrossed for five generations, and animals were genotyped according to protocols provided by the Colonna laboratory (Colonna, 2003). Immunostaining for TREM2 documented the absence of TREM2 protein in the brains of $\mathrm{KO}$ mice. Cerebral vasculature was delineated by the injection of carbon black, and plasticity of the posterior communicating arteries (Kawase et al., 1999; Webster et al., 2013). Wild-type male littermates and wild-type male C57BL/6 mice (genetic background of the KO colony) were also compared for any differences in brain and cerebrovascular anatomy. Pilot studies of the stroke model were also performed to determine whether there were any differences between C57BL/6 mice and WT littermates for lesion size, behavior, and cerebral blood flow (CBF; see below for methods used), and none were found (data not shown). Thus, C57BL/6 mice (WT mice) were used for comparison to the KO mice.

\section{Mouse stroke model}

All surgical techniques were performed under aseptic conditions. For the study, 8-to 10-week-old KO and WT mice weighing 20-25 g were used. Anesthesia was induced by inhalation of $3.0 \%$ isoflurane in $\mathrm{N}^{2} / \mathrm{O}_{2}(80 \%$ : $20 \%)$; a surgical procedure was performed under spontaneous ventilation in $2.0-2.5 \%$ isoflurane in $\mathrm{N} 2 / \mathrm{O}_{2}$ (80\%:20\%). Surgical planes of anesthesia were assessed by the absence of hindleg withdrawal in response to a pinch. A $1 \mathrm{~cm}$ skin incision was created between the left margin of the orbit and the tragus, and the temporalis muscle was incised. A focal cerebral infarct was induced by permanent occlusion of the distal left middle cerebral artery (dMCAO) as previously described (Kawabori et al., 2013a,b). A small craniotomy was made above the proximal segment of middle cerebral artery (MCA), and the MCA was exposed after the dura was opened and retracted. The MCA was occluded by coagulation at the MCA segment just proximal to the olfactory branch, which was consistently present. Rectal temperature was maintained between $36.5^{\circ} \mathrm{C}$ and $37.5^{\circ} \mathrm{C}$ during the procedures by using a thermometer connected to a heating pad (Harvard Apparatus). To confirm whether there were differences between genotypes in CBF reduction during MCA occlusion or not, CBFs of a separate set of six mice were studied. CBF was studied using laser Doppler flowmetry (OXYLAB LIF, OXFORD OPTRONIX). Two $1.5 \mathrm{~mm}$ holes were drilled $3 \mathrm{~mm}$ lateral and $1 \mathrm{~mm}$ caudal from bregma, and the dura was opened carefully. The laser Doppler probe was secured perpendicular to the brain surface. Ten readings ( $2 \mathrm{~s}$ apart) of local $\mathrm{CBF}(\mathrm{CBBF})$ were collected from the digital display of the laser Doppler flowmetry unit and were averaged to provide an 1 CBF value. The initial CBF reading was recorded as $100 \%$, and subsequent flow changes ( 5 and 30 min post-MCAO) were expressed relative to this value, as previously described (Webster et al., 2013). At the end of the surgical procedure, incision sites were closed and animals were allowed to recover. Mice were returned to their cages and allowed free access to food and water, and were housed in a climate-controlled environment $\left(25^{\circ} \mathrm{C}\right)$.

\section{Behavior studies}

Bederson score. The Bederson score was modified for use in mice, as previously reported (Yenari et al., 2006; Tang et al., 2007, 2011; Zheng et al., 2008; grade $0=$ no observable neurological deficit; grade $1=$ unable to extend the contralateral forelimb; grade 2 = flexion of the contralateral forelimb; grade $3=$ mild circling to the contralateral side; grade $4=$ severe circling; and grade $5=$ falling to the contralateral side).

Ladder test. The ladder test was performed as described previously (Tang et al., 2007). A ladder composed of 40 rungs with a $1 \mathrm{~mm}$ diameter and $2 \mathrm{~cm}$ intervals was constructed. The ladder was placed between two transparent acrylic walls spaced $4 \mathrm{~cm}$ apart, so that once the mouse was placed on the ladder, it could only move straight ahead. The ladder was placed at a $30^{\circ}$ slope, and the animal was encouraged to move forward and upward. Each weight-bearing step was recorded by a video camera placed underneath the ladder. The number of forelimb faults associated with each weight bearing step was then reviewed and tabulated.

\section{Histological examination}

After animals were killed with a anesthesia overdose, they were perfused with ice-cold PBS, and the brain was harvested. Brains were sunk in $20 \%$ sucrose overnight and frozen at $-80^{\circ} \mathrm{C}$ and stored until use. Fresh-frozen sections were cryosectioned in the coronal plane (25 $\mu \mathrm{m}$ thick).

\section{Histochemistry and fluorescent microscopy}

Brain sections were stained with cresyl violet to measure infarct size and brain resorption/atrophy as previously described (Kawabori et al., 2012, 2013b). Coronal sections from six brain regions (between $1.5 \mathrm{~mm}$ anterior and $1.5 \mathrm{~mm}$ posterior to the bregma) were collected at $500 \mu \mathrm{m}$ intervals throughout the ischemic lesion and stained with cresyl violet. The infarct areas in each section were measured using an image analysis system (ImageJ) and calculated by subtracting the normal ipsilateral area from that of the contralateral hemisphere to reduce errors due to cerebral swelling ( $n=8$ each). Tissue sections were immunostained for TREM2 (1:10; MAB17291, R\&D Systems), and its ligands were identified by the application of TREM2 fusion protein. TREM2 fusion protein is purified TREM2 covalently linked to human Fc (50 $\mu \mathrm{g} / 500 \mu \mathrm{l} ; 1729-\mathrm{T} 2, \mathrm{R} \& \mathrm{D}$ Systems). In some cases, the fusion protein was labeled with Texas red (per Nick Cairns, Combinex). Sections were colabeled with the neuronal marker NeuN (1:50; Millipore) or the CD11b microglial/monocyte marker (1:50; ab75476, Abcam), then reacted with fluorescently labeled secondary antibodies. Activated microglia and phagocytic microglia were also identified using peroxidase-labeled Griffonia simplicifolia isolectin-B4 (IB4) $(10 \mu \mathrm{g} / \mathrm{ml}$; L5391, Sigma), or with CD68 rat antimouse monoclonal antibody (1:200; ab53444, Abcam), respectively, followed by diaminobenzidine (Vector Laboratories). The sections were then counterstained with hematoxylin. Oil red O staining (O0625, Sigma) was used to visualize the lipid-rich foamy macrophages according to the instructions of the manufacturer followed by hematoxylin counterstaining. TUNEL staining was performed to delineate any interactions between phagocytic microglia (CD68) and necrotic/apoptotic cells according to the directions of the manufacturer (S7100, Millipore). To assess the extent of angiogenesis after ischemia, the density of the collagen IV (1:100; ab6586, Abcam)-positive microvessels were examined as previously described (Ito et al., 2012). The expression of reactive glia, glial scarring, and glial cells was examined using an antibody against GFAP (1:100; catalog \#3655, Cell Signaling Technology), and neurons were examined using an antibody against MAP2 (1:200; AB2290A4, Millipore), as previously described (Kawabori et al., 2013a). Positive cells were countered under optical microscopy (BX-53 microscope, Olympus) or laser confocal microscopy (LSM510, Zeiss), as previously described (Tang et al., 2011; Kawabori et al., 2013b). Briefly, a section $1 \mathrm{~mm}$ anterior to the bregma was used to quantify the cell numbers, and the positive cells were optically counted from its five random nonoverlapping $400 \times$ high-power fields (HPFs) within the cortex adjacent to the outer boundary of the infarct, as delineated by hematoxylin in four mice for each groups. In the case of dense cell aggregation, the cells were counted based on the presence of nuclear staining by hematoxylin with DAB surrounding cytoplasm. Semi-quantification of the immunofluorescent studies was conducted by choosing a random non-overlapping 

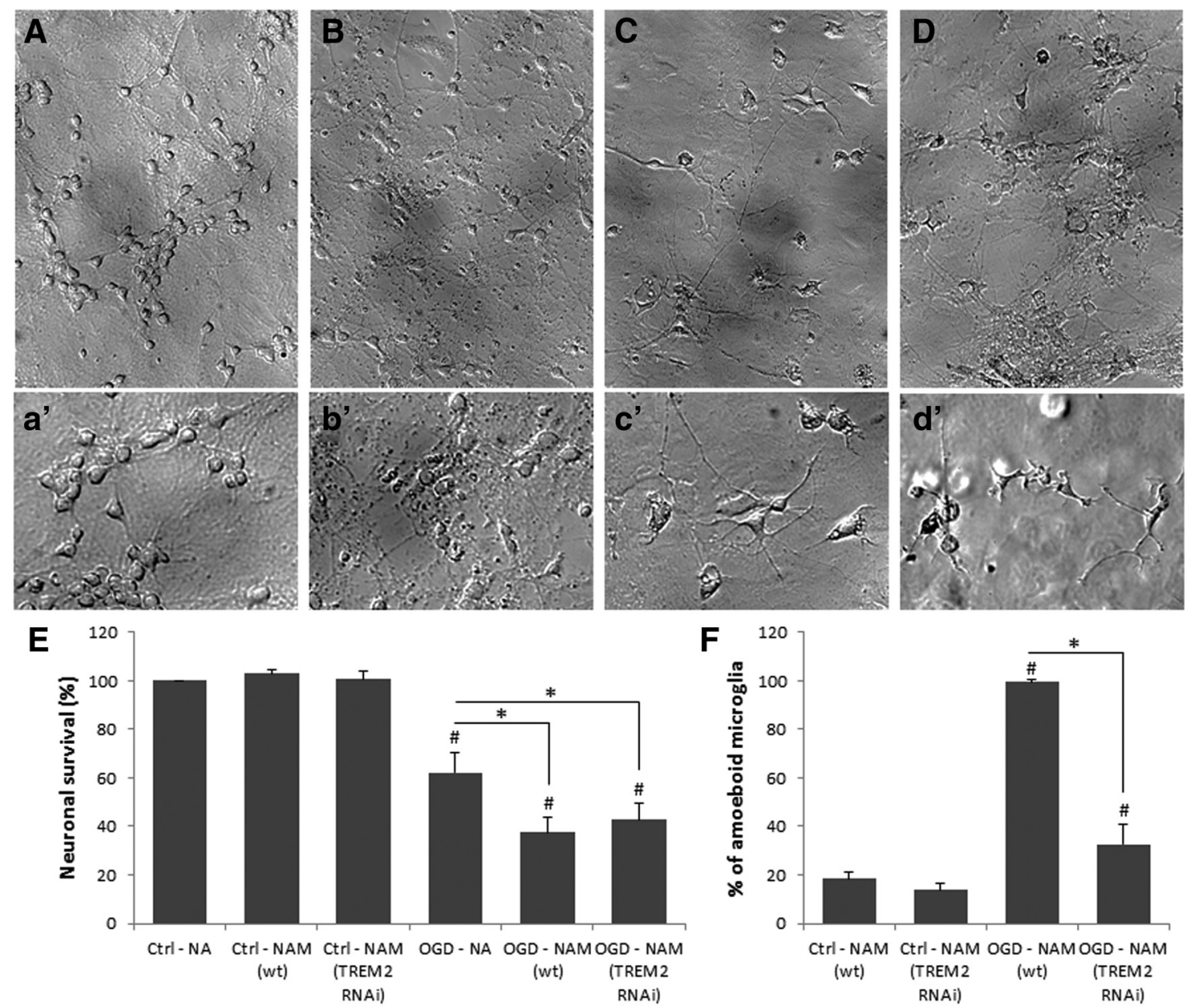

Figure 1. TREM2 knockdown with RNAi reduces microglial activation, but does not affect acute neuron survival. Primary NA cultures with and without microglia were prepared. TREM2 was knocked down by RNAi or control RNAi, and some cultures were exposed to $1 \mathrm{~h}$ OGD followed by $24 \mathrm{~h}$ reperfusion at normoxia and $5.5 \mathrm{~mm}$ added glucose. $\boldsymbol{A}$, NA uninjured cultures (Ctrl-NA). $\boldsymbol{B}$, NA cultures exposed to $0 G D$ for $1 \mathrm{~h}$ and reperfusion for $24 \mathrm{~h}$. C, NAM cultures (control RNAi) after OGD [OGD NAM (WT)]. D, NA cultures plus TREM2-deficient microglia were subjected to 0GD (OGD NAM TREM2). Neuronal processes were more fragmented in the absence of microglia or TREM2-deficient microglia. Higher-power micrographs $\left(\boldsymbol{a}^{\prime}-\boldsymbol{d}^{\prime}\right)$ show neuronal processes and/or microglial morphology under the different conditions described in $\boldsymbol{A}-\boldsymbol{D}$. Arrowheads show microglia, where they appear amoeboid ( $\boldsymbol{c}^{\prime}$, OGD, control RNAi) and ramified ( $\boldsymbol{d}^{\prime}, 0 \mathrm{OGD}$, TREM2 RNAi). $\boldsymbol{E}$, Neuronal survival/viability is decreased by OGD in all cases. The addition of microglia, whether with intact TREM2 (WT) or deficient in TREM2 (TREM2 RNAi), led to decreased neuron survival. $\boldsymbol{F}$, Microglial activation, as assessed by the transformation of resting (ramified) microglia into amoeboid microglia, is increased by OGD and markedly decreased in TREM2 deficiency. \#p $<0.01$ compared with control conditions; ${ }^{*} p<0.01$ as indicated, $n=4 /$ group.

$200 \times$ high-power field near the infarct boundary. Then, the area of positive signal was binarized (as a black signal on a white background) and quantified using an image analysis system (ImageJ), as previously described (Ito et al., 2012).

\section{Modified chromatin immunoprecipitation assay}

Modified chromatin immunoprecipitation (ChIP) assays were conducted to clarify whether nucleic acids might be an endogenous ligand for TREM2 according to the instructions of the manufacturer (Miltenyi Biotec) with modifications. Whole mouse brains were obtained $7 \mathrm{~d}$ postdMCAO, separated into hemispheres, then snap frozen in liquid nitrogen. Hemispheres were thawed in cold fractionation buffer $(320 \mathrm{~nm}$ sucrose, 20 mM HEPES 7.4, 1 mM EGTA, 1 mM PMSF, protease inhibitor cocktail; catalog \#8340, Sigma) then homogenized. Debris and nuclei were cleared at $800 \times g$ at $4^{\circ} \mathrm{C}$ for $30 \mathrm{~min}$. Homogenate $(100 \mu \mathrm{l})$ was then incubated with $2 \mu \mathrm{g}$ of TREM 2 fusion protein with human Fc overnight, cross-linked with $5 \mu \mathrm{l}$ of $2 \%$ glutaraldehyde, then quenched with $10 \mu \mathrm{l} 10$ м Tris- $\mathrm{HCl}, \mathrm{pH} 8$. After $50 \mu \mathrm{l}$ of protein $\mathrm{G}$ microbeads were added (Miltenyi Biotech) and protein G microbead TREM2Fc conjugates were isolated using the Miltenyi uMacs Separator and uColumns according to the instructions of the manufacturer. Immunoprecipitates were washed and eluted by $50 \mathrm{~mm}$ Tris $\mathrm{HCl}$ and were run with $2 \%$ agarose gel containing SYBR green.
Statistical analysis

All experimental groups were studied in a randomized fashion, and ratings and lesion analyses were performed by investigators blinded to the experimental conditions. All statistical analyses were performed using SigmaStat version 3.1 (Systat Software). Quantitative data were presented as the mean $\pm \mathrm{SE}$. The differences between the two groups were compared using an unpaired $t$ test, and multiple comparisons were performed using one-way ANOVA followed by Bonferroni's post hoc test. A $p$ value of $<0.05$ was considered to be statistically significant.

\section{Results}

Microglia deficient in TREM2 showed less activation and failed to phagocytose OGD-exposed neurons

Primary mixed cultures of neurons, astrocytes, and microglia were prepared and exposed to OGD. OGD led to decreased neuron survival, and this was exacerbated in the presence of microglia. TREM2 deficiency did not affect neuron survival at $24 \mathrm{~h}$ post-OGD exposure (Fig. 1A-E). Morphology among TREM2deficient microglia was significantly more ramified (Fig. 1D,F) compared with the WT microglia, which tended to assume a more amoeboid morphology (Fig. 1C,F). 

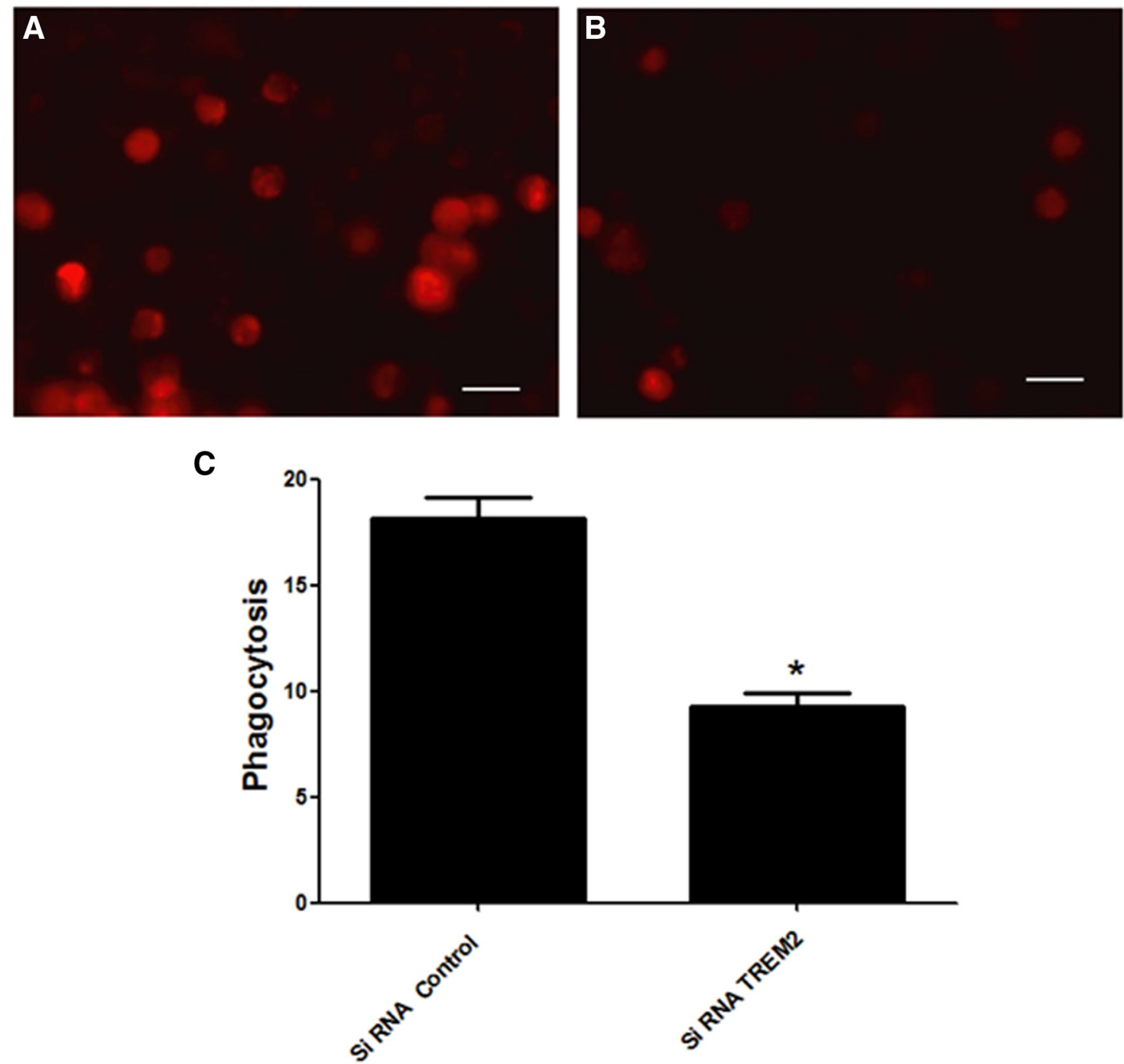

Figure 2. TREM2 deficiency blunts phagocytosis of OGD-exposed neurons by microglia. Lysates from CM-Dil-loaded, OGD-exposed neuro 2 A cells were applied to BV2 microglia. A, BV2 cells with intact TREM2 show avid uptake of neuro 2A lysates (red). B, When TREM2 was knocked down using siRNA, fewer microglia took up neuron 2A lysates, as evidenced by less red staining. $C$, Counts of positive red cells, which indicate that TREM2 2 is required for the uptake of OGD-exposed neuro $2 \mathrm{~A}$ cells. Scale bar, $100 \mu \mathrm{m}$. Data are mean \pm SEM. ${ }^{*} p<0.05$.

We then assessed the phagocytic function of microglial TREM2 when treated with OGD-exposed neurons. Microglial BV2 cells were subjected to TREM2 gene knockdown using siRNA. Control BV2 cells were transfected with scrambled siRNA. CM-DiI-loaded neuro 2A cells were exposed to OGD then transferred to the BV2 cells. Control microglial BV2 cells took up injured neurons, as evidenced by the abundance of CM-DiI-positive BV2 cells (Fig. 2A). In contrast, TREM2deficient microglia (Fig. $2 B$ ) showed significantly blunted phagocytosis of the injured cells (Fig. 2C).

\section{Expression of TREM2 and its ligand in experimental stroke} Brain sections of WT mice were stained with an antibody against TREM2 and TREM2-Fc fusion protein labeled with Texas red plus cell-type markers. TREM2 was highly expressed in the ipsilateral ischemic brain within the peri-infarct zones (Fig. $3 B, D$ ); few TREM2-positive cells were observed on the contralateral nonischemic side (Fig. 3A,C). Furthermore, TREM2-positive cells colocalized to CD11b-positive microglia (Fig. 3B, arrows), but not to NeuN-positive neurons (Fig. 3D). The time course of TREM2 ex- pression was shown to peak at $7 \mathrm{~d}$ after ischemia, with positive cells still present at $14 \mathrm{~d}$, and few positive cells present by $30 \mathrm{~d}$ (Fig. $3 E$ ).

To determine whether the ischemic brain contained a ligand for TREM2, we used a TREM2 fusion protein labeled with Texas red to identify TREM2 binding partners. Upregulation of a TREM2 ligand was found in the ischemic brain (Fig. 4B). Lack of fusion protein binding in the contralateral, uninjured side is shown for comparison (Fig. 4A). TREM2 fusion protein was bound to neurons after ischemia (Fig. 4G-J), while little TREM2 binding was observed in the nonischemic brain (Fig. $4 C-F$ ). These data suggest that ischemic neurons express a ligand to which TREM2 binds.

\section{TREM2 KO mice had worsened neurological recovery and less} brain resorption

Carbon black perfusion failed to show any significant differences in the cerebral vasculature of TREM KO and WT mice (data not shown). No obvious behavioral phenotype was noted in the TREM2 KO mice before injury. There was no difference in lCBF during the surgery, as monitored by laser Doppler flowmetry between the groups ( 5 and 30 min post-dMCAO consecutively: 


\section{Contralateral}
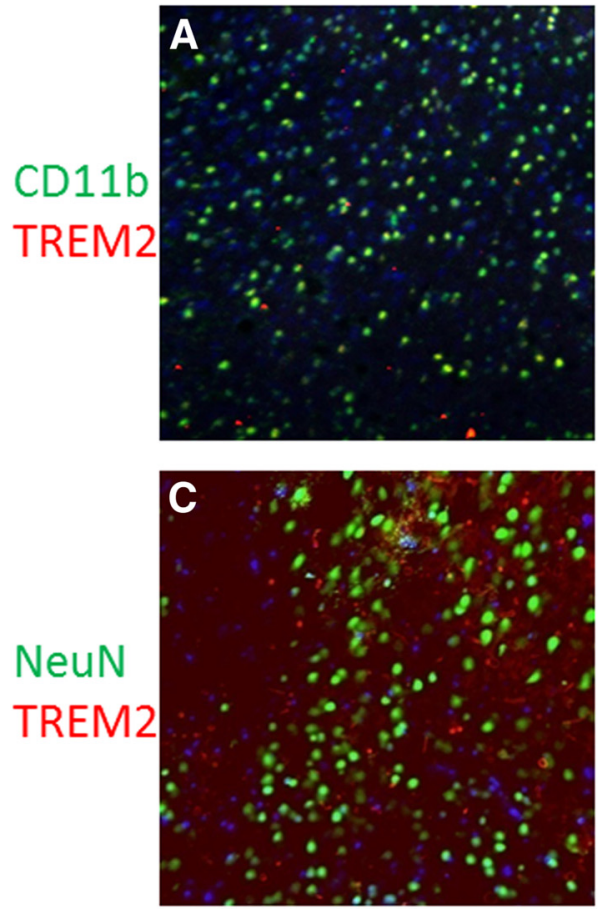

ipsilateral
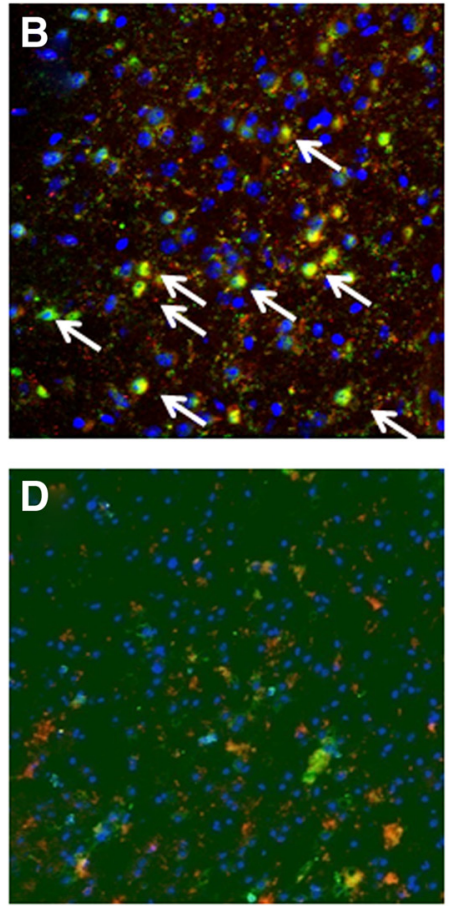

\section{E TREM-2 expression following MCAO}

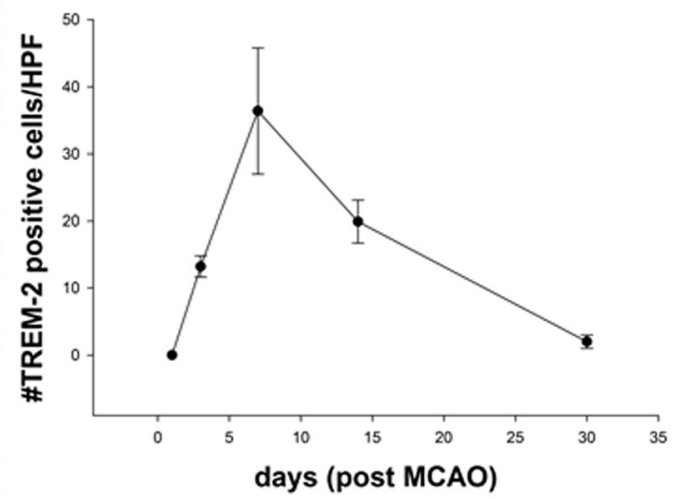

Figure 3. TREM2 is expressed in microglia within the ischemic borderzone. $A-D$, Immunostains for TREM2 (red) and neuronal (NeuN, green) and microglial (CD11b, green, arrows) markers $7 \mathrm{~d}$ post-MCA0 show that TREM2 is present in microglia but not in neurons. Colocalized cells appear yellow. TREM2-positive cells (red) are especially expressed in the ipsilateral ischemic brain $(\boldsymbol{B}, \boldsymbol{D})$, and less so, on the contralateral side $(\boldsymbol{A}, \boldsymbol{C}$. $\boldsymbol{E}$, The time course of TREM2 expression is shown. Numbers of TREM2-positive cells peaked at $7 \mathrm{~d}$, but were present as early as $3 \mathrm{~d}$, and persisted at $14 \mathrm{~d}$. By $30 \mathrm{~d}$, the numbers of TREM2-positive cells were similar to baseline.
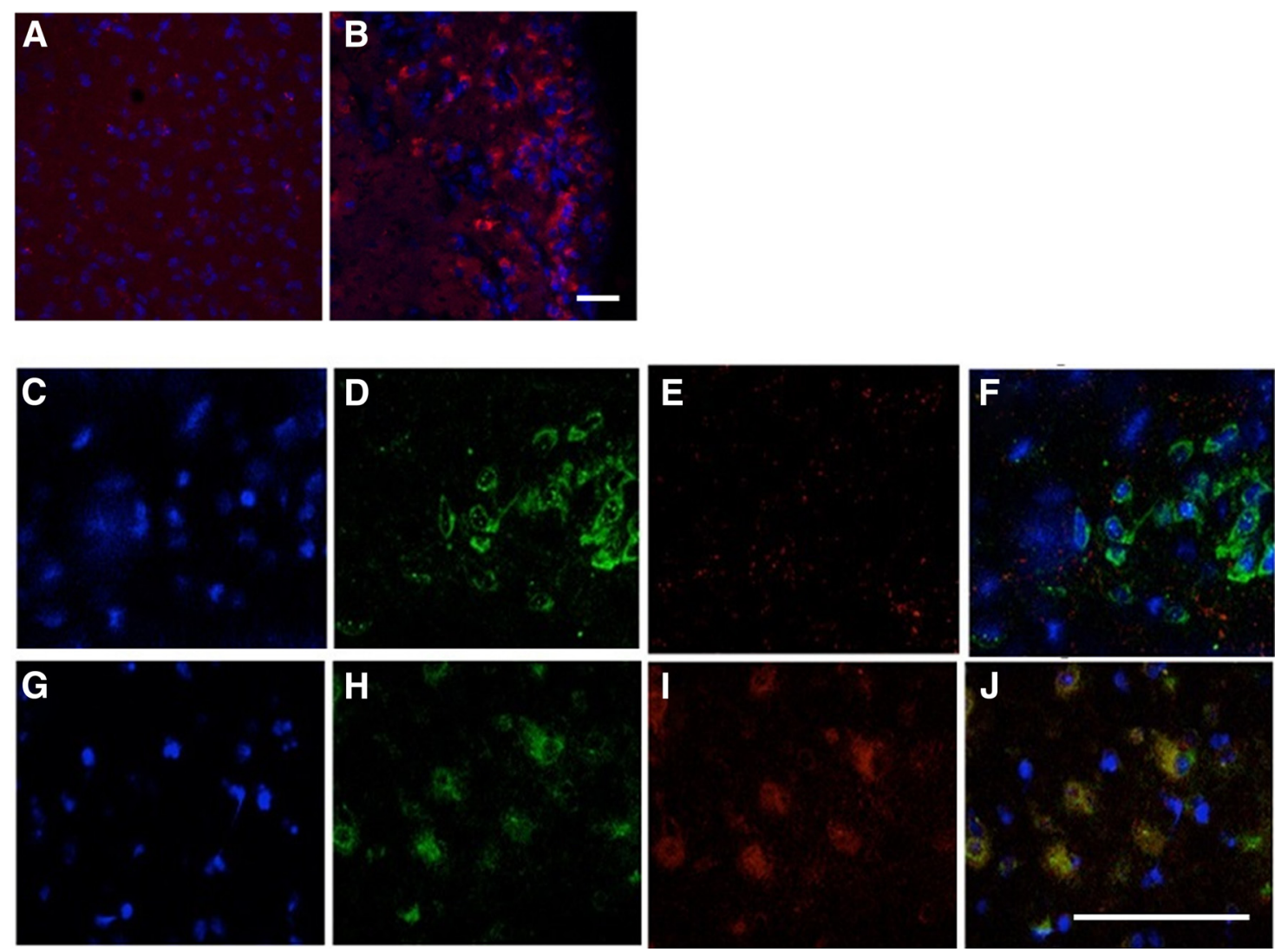

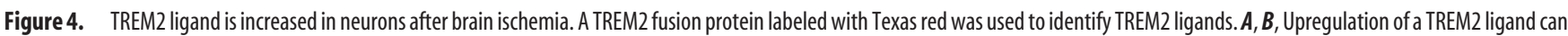
be found in the ischemic brain $7 \mathrm{~d}$ post-MCA0 exposure $(\boldsymbol{B}$, red), compared with the contralateral side $(\boldsymbol{A})$. $\mathbf{G}-\boldsymbol{J}$, The TREM2 fusion protein colocalized to neurons after ischemia. $\boldsymbol{C}-\boldsymbol{F}$, In the contralateral brain, very little TREM2 ligand was present (blue, DAPI; green, NeuN; red, TREM2 fusion protein with Texas red; merged, $\boldsymbol{F}, \boldsymbol{J})$. Scale bar, $80 \mu \mathrm{m}$. 

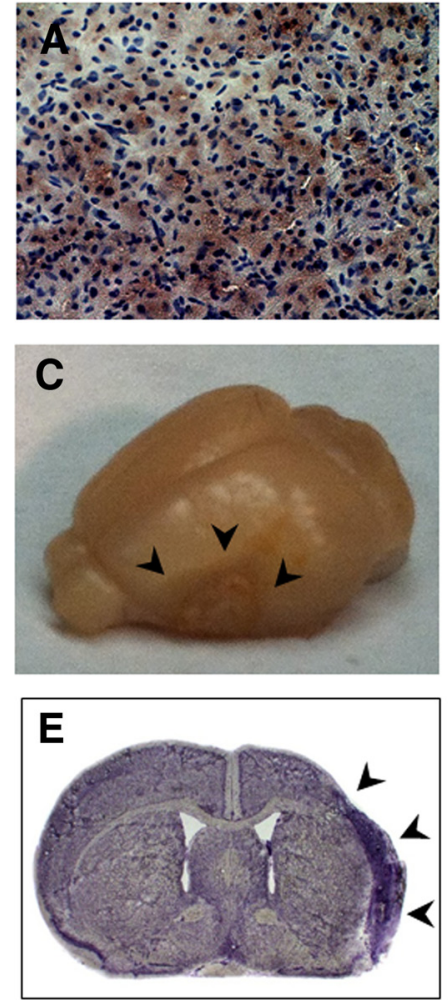
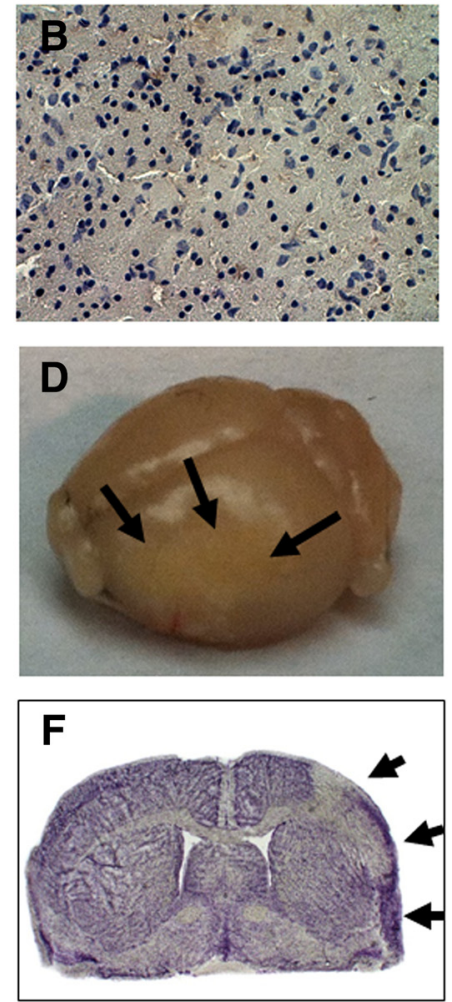
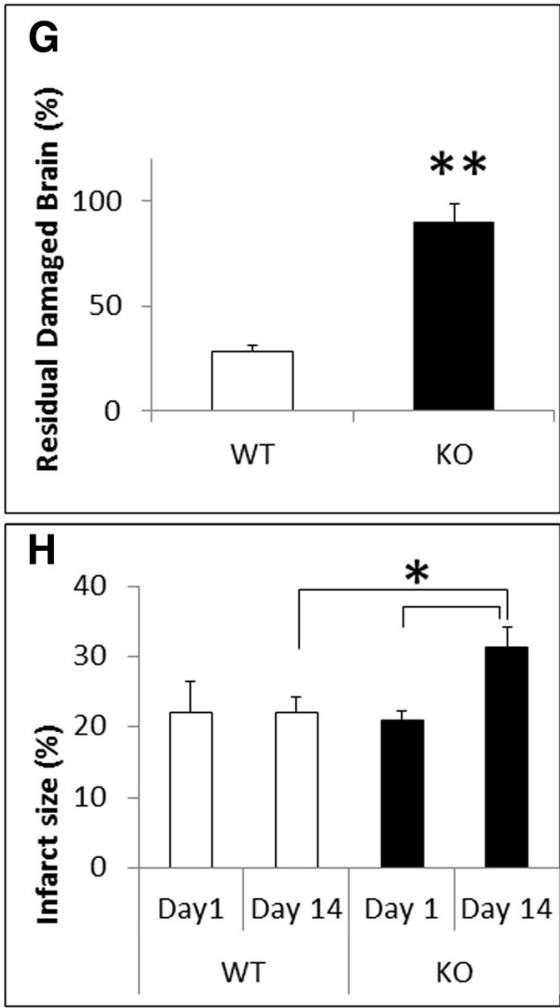

Figure 5. Less infarcted brain resorption and larger infarct size were observed in TREM2-deficient mice. $\boldsymbol{A}, \boldsymbol{B}$, Brains of TREM2 KO mice $(\boldsymbol{B})$ had very little to no TREM2 protein compared with WT mice (A). C, E, WT mice showed brain resorption post-dMCA0 at day 14 (arrowheads). $\boldsymbol{D}, \boldsymbol{F}$, In contrast, TREM2 K0 mice showed significantly less resorption (arrow). G, Quantification of residual infarcted brain was estimated to be $\sim 30 \%$ in the WT group, whereas most of the damaged brain was still present in the $\mathrm{KO}$ group. $\boldsymbol{H}$, Overall infarct size was also significantly larger in the $K 0$ group. ${ }^{* *} p<0.01,{ }^{*} p<0.05, n=12 /$ group.

A

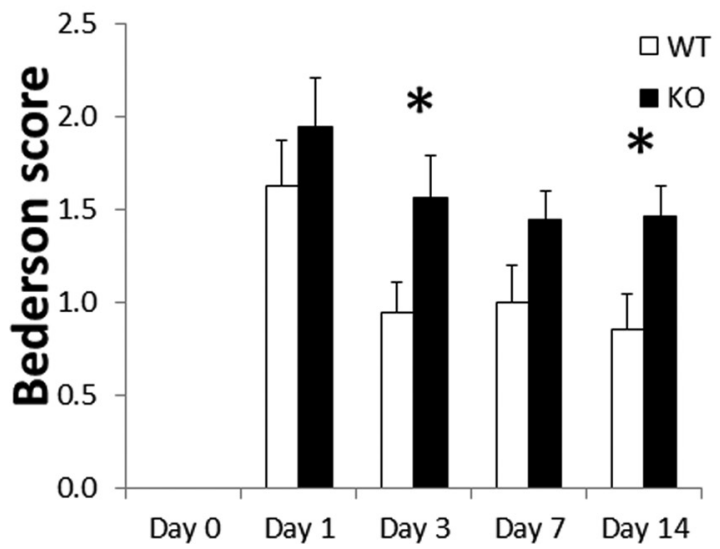

B

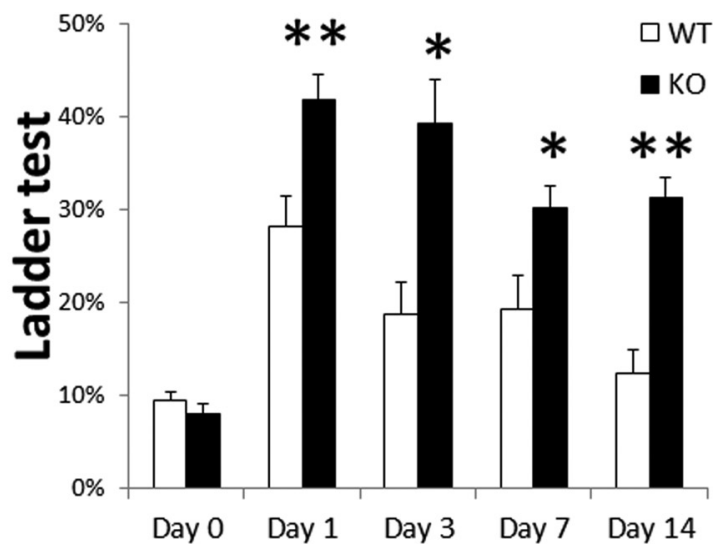

Figure 6. TREM2-deficient mice showed worsened neurological recovery compared with wild-type mice. $A, B$, Neurological deficits were assessed using a modified Bederson score and the number of foot faults on the ladder test. TREM2 KO (KO) mice showed worse scores on the Bederson scale compared with WT mice $(\boldsymbol{A})$, and made more foot faults on the ladder test $(\boldsymbol{B}) .{ }^{* *} p<0.01,{ }^{*} p<0.05, n=12 /$ group.

WT mice, $29.8 \pm 8.2 \%$ and $28.1 \pm 8.7 \%$; KO mice, $23.9 \pm 12.2 \%$ and $23.0 \pm 5.5 \%$ ). Brains of TREM $2 \mathrm{KO}$ (Fig. $5 B$ ) mice had very little to no TREM2 protein compared with WT mice (Fig. 5A). WT mice showed marked brain resorption post-dMCAO at day 14 (Fig. 5C,E, arrowheads indicate the area of resorption), while TREM2 $\mathrm{KO}$ mice showed less resorption (Fig. 5D,E, arrow). The fraction of residual ischemic brain at day 14 was $28.1 \pm 2.9 \%$ in the WT group, compared with $89.9 \pm 8.8 \%$ in the TREM2 KO group (Fig. 5G). Further, overall infarct size was no different between groups at day 1 (WT mice, $22.2 \pm 4.3 \%$; KO mice, $20.9 \pm 1.4 \%$ ), but was significantly larger in the $\mathrm{KO}$ group at day $14(31.5 \pm 2.7 \%)$ compared with the WT group on day $14(22.1 \pm 2.3 \%$; Fig. $5 H)$.

Consistent with histological observations, TREM2 KO mice showed worsened neurological deficits in both the Bederson score and performance on the ladder test (Fig. 6A,B).

Activated microglia and phagocytes were decreased in TREM2 KO mice

Activated microglia identified by IB4 staining were counted at the infarct border (Fig. $7 A-D$ ). The number of activated microglia 
A

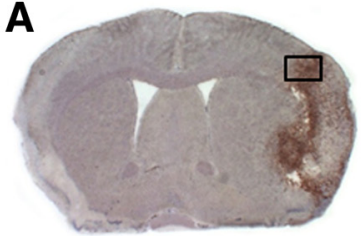

IB4
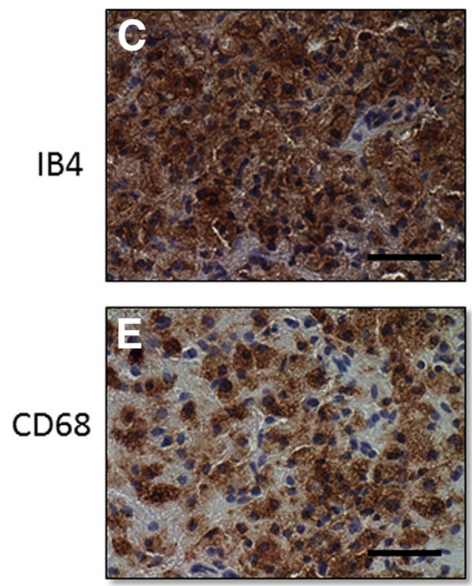

B
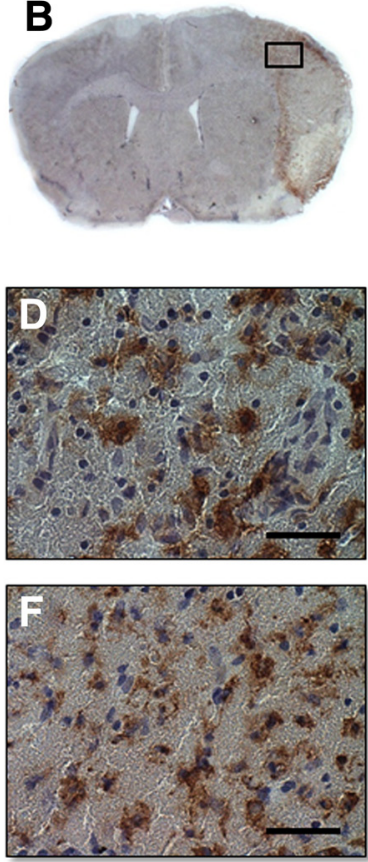

G
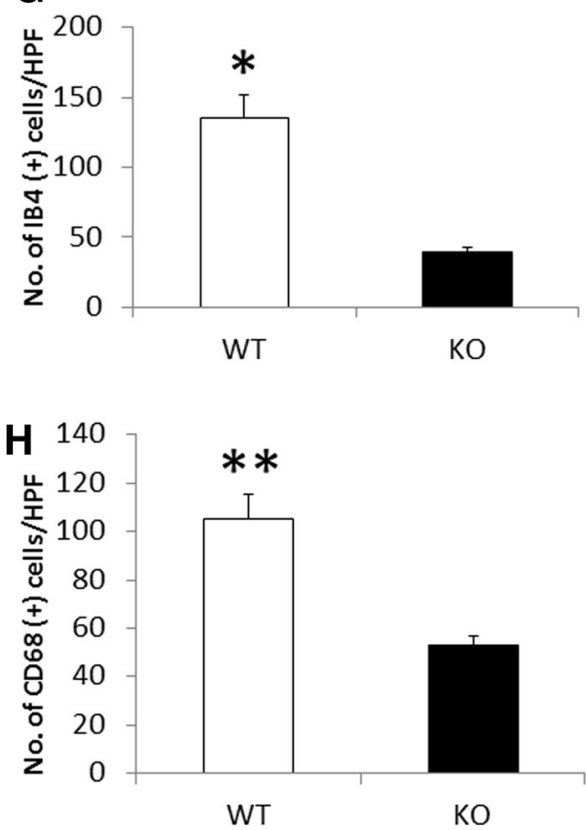

Figure 7. Activated microglia and phagocytes were decreased in TREM2-deficient mice. $\boldsymbol{A}-\boldsymbol{H}$, Activated microglia identified by IB4 staining [WT mice, $\boldsymbol{A}, \boldsymbol{C} ;$ TREM2 K0 mice (KO), $\boldsymbol{B}, \boldsymbol{D}]$ and phagocytic microglia by $C D 68$ staining (WT mice, $\boldsymbol{E} ; \mathrm{KO}$ mice, $\boldsymbol{F}$ ) were significantly decreased in TREM2 K0 groups ( $\boldsymbol{G}$ and $\boldsymbol{H}$, respectively). Most of the activated cells were observed in and around the infarct border. Images were collected from brains on day 7 poststroke. Scale bar, $40 \mu \mathrm{m} .{ }^{* *} p<0.01,{ }^{*} p<0.05, n=8$ /group.
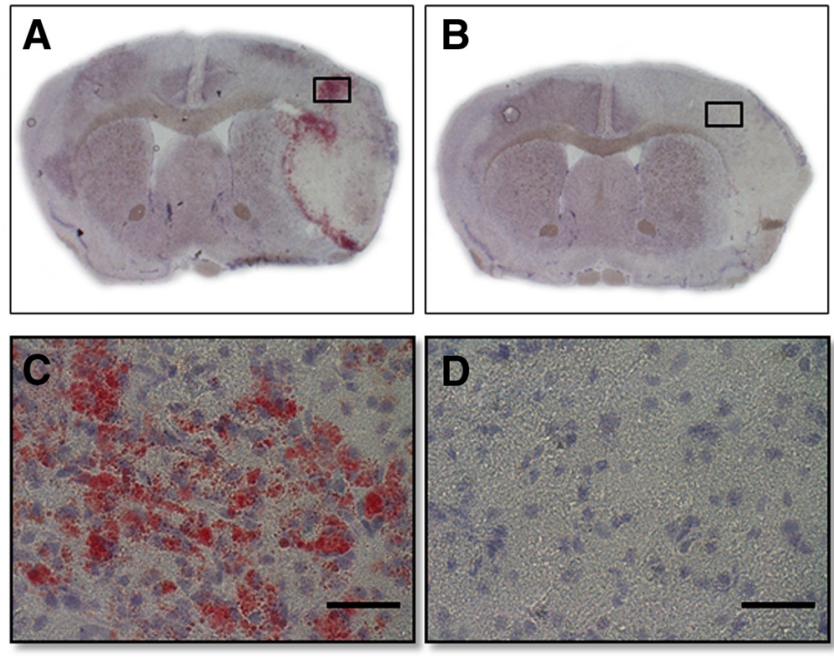

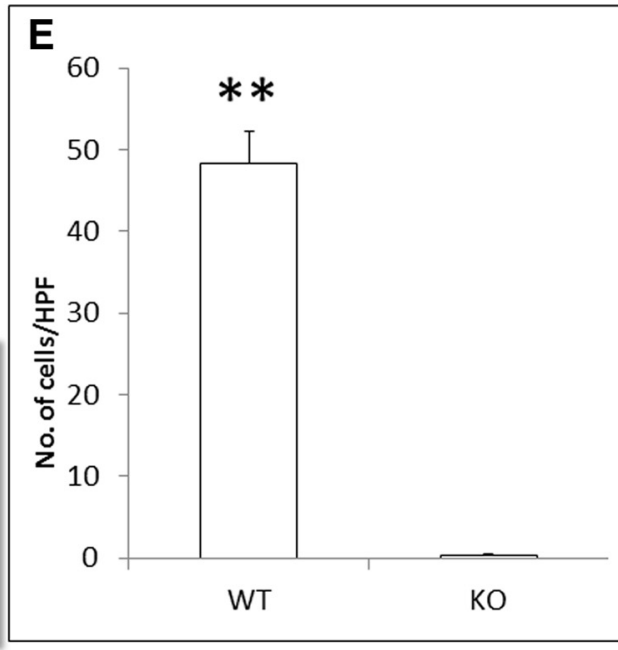

Figure 8. Oil red 0 staining shows fewer lipid-rich foamy macrophages in TREM2-deficient mice. Oil red 0 stain is used here to delineate foamy macrophages, or foam cells in red, in brains $7 \mathrm{~d}$ post-MCAO. These represent phagocytes that contain intracellular lipids, which result from the phagocytosis of injured brain. $\boldsymbol{A}-\boldsymbol{D}$, Lipid-rich foamy macrophages can be found in and around the infarct border in WT mice $(\boldsymbol{A}, \boldsymbol{C})$, while there were almost no foamy macrophages found in the TREM2 KO mice $(\boldsymbol{B}, \boldsymbol{D})$. $\boldsymbol{E}$, Numbers of red foam cells were nearly absent in the TREM2 KO mice (KO), and would suggest that phagocytosis of the injured brain cells was significantly impaired in these mice. Scale bar, $40 \mu \mathrm{m} .{ }^{* *} p<0.01, n=8 /$ group.

(as identified by dark IB4 staining) was significantly decreased in the TREM2 KO group (Fig. $7 B, D, 39.3 \pm 3.1$ cells/HPF) compared with the WT group (Fig. $7 A, C, 135.3 \pm 16.8$ cells/HPF). This is shown graphically in Figure $7 G$. Consistent with this result, phagocytic microglia, detected by CD68 staining (WT mice, Fig. $7 E$; $\mathrm{KO}$ mice, Fig. $7 F$ ) were also significantly decreased in TREM2 KO groups (KO mice, $52.8 \pm 4.3$ cells/HPF; WT mice, $105 \pm 10.2$ cells/HPF; Fig. $7 H$ ). Oil red $\mathrm{O}$ staining was used to delineate intracellular lipids within phagocytes ("foamy macrophages") as an indicator of ischemic brain uptake. Numerous lipid-rich foamy macrophages were found at around the infarction border in the WT mice $(48.3 \pm 4.1$ cells/HPF; Fig. $8 A, C)$, while there were almost no foamy macrophages found in the TREM2 KO group $(0.3 \pm 0.3$ cells/HPF; Fig. $8 B, D)$. This indicates that phagocytosis of the ischemic brain was markedly impaired in the TREM2 KO mice (Fig. $8 E$ ).

Colabeling with CD68 to identify phagocytes and with TUNEL to identify dying cells was performed to document phagocytosis of injured cells. 3D confocal imaging showed that CD68-positive phagocytes frequently contacted TUNEL-positive cells in WT brains (37.5 $\pm 1.1 \%$; Fig. 9A-C). In contrast, CD68positive cells often remained separate from TUNEL-positive cells in the brains of TREM2 KO mice (3.8 $\pm 1.1 \%$; Fig. $9 D-F)$. The proportion of CD68-positive cells contacting TUNEL-positive 

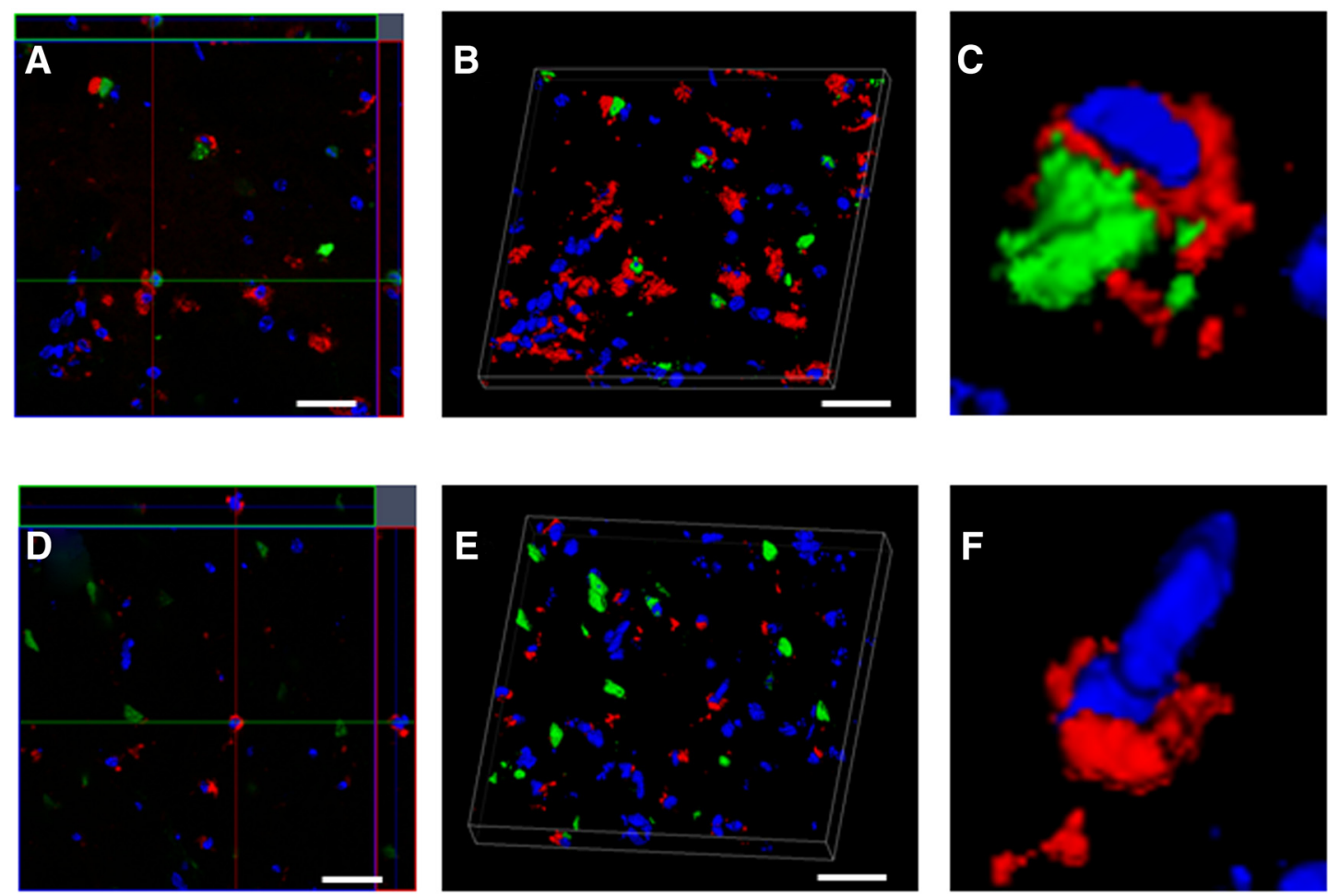

G
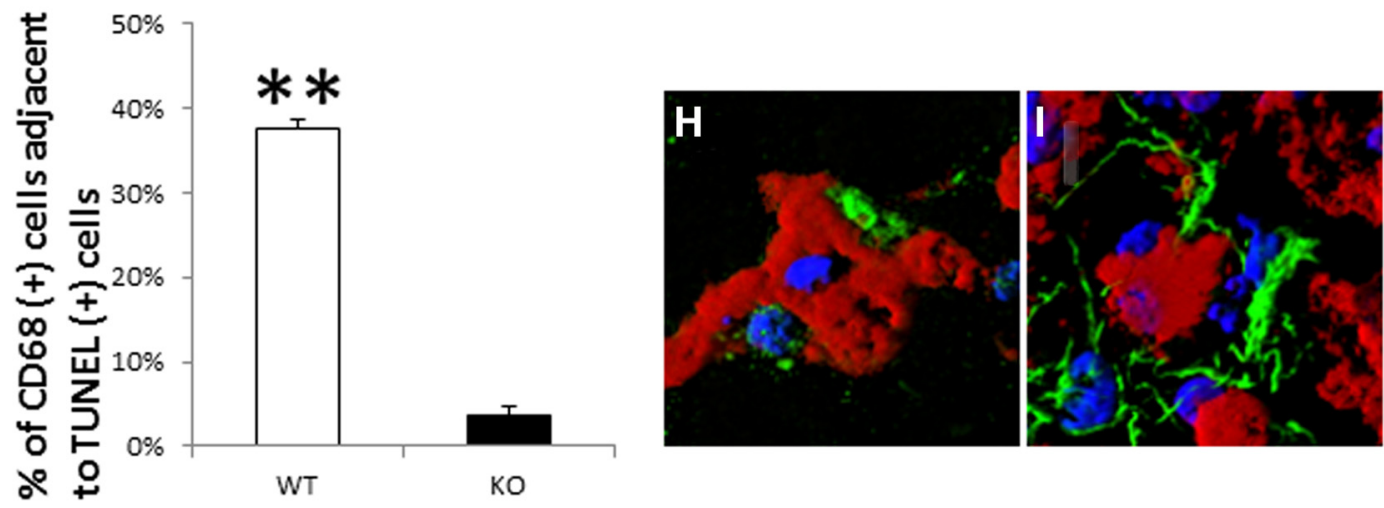

Figure 9. Fewer phagocytes associate with TUNEL-positive cells in TREM2-deficient mice. A-C, A 3D rendering confocal image shows CD68-positive (red) phagocytes contacting TUNEL-positive cells (green) in a WT brain (DAPI in blue) $7 \mathrm{~d}$ post-MCA0. D-F, In contrast, CD68-positive cells tended to remain separate from TUNEL-positive cells in TREM2-deficient brains. G, The proportion of CD68-positive cells contacting TUNEL-positive cells was markedly reduced in TREM2-deficient brains. CD68-positive phagocytes (red) contact both MAP2 (green)-positive neurons (H) and GFAP (green)-positive glia (I) surrounding the infarct border. Scale bar, $80 \mu \mathrm{m} .{ }^{* *} p<0.01, n=4 /$ group.

cells was much lower in the TREM2 KO ischemic brains compared with WT brains (Fig. 9G), suggesting that microglia phagocytose injured cells, and this is dependent upon TREM2. CD68-positive phagocytes appear to contact both neurons and astrocytes, although the extent of contact with astrocytes was much less than that of neurons (Fig. 9H,I).

Angiogenesis but not reactive glial scarring was decreased in TREM2 KO mice

To identify the relationship between the microglia/macrophage debris clearance and functional outcome, angiogenesis and reactive glial staining were examined. Collagen IV-positive parenchymal microvessels were significantly increased in the WT group $(6.4 \pm 0.5 \%$; Fig. $10 A, C)$ compared with the $\mathrm{KO}$ group $(4.5 \pm$ $0.2 \%$; Fig. $10 B, D$ ) at the infarct border (Fig. 10E; $p<0.01$ ). The extent of glial scarring, as assessed by GFAP staining, at the infarct border was somewhat decreased in the KO group (Fig. 10G,I) compared with the WT group, but was not statistically different.

\section{Potential endogenous ligand of TREM2 in brain ischemia}

To determine potential binding partners of TREM2 in the ischemic brain, we reacted the TREM2 fusion protein with samples of ischemic brain to pull down potential molecules that bound TREM2. Since nucleic acids have previously been shown to bind various innate immune receptors, including the Toll-like receptors (TLRs), we performed a modified ChIP assay. This assay was performed on whole-brain lysates of the ischemic hemisphere $7 \mathrm{~d}$ after ischemic insult. This assay showed that TREM2 fusion protein associated with high-molecular-weight nucleic acids (Fig. 11A).

We then used an in vitro assay to validate whether nucleic acids are capable of eliciting functional TREM2 signaling. BWZ 

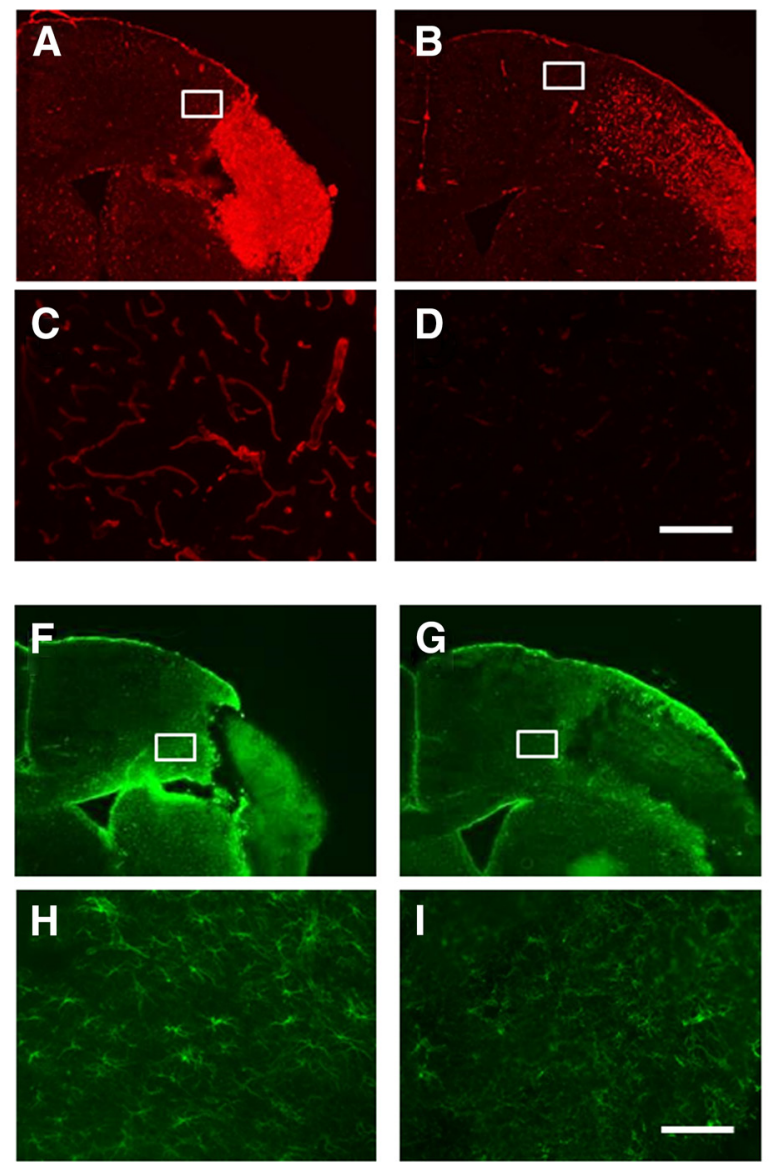
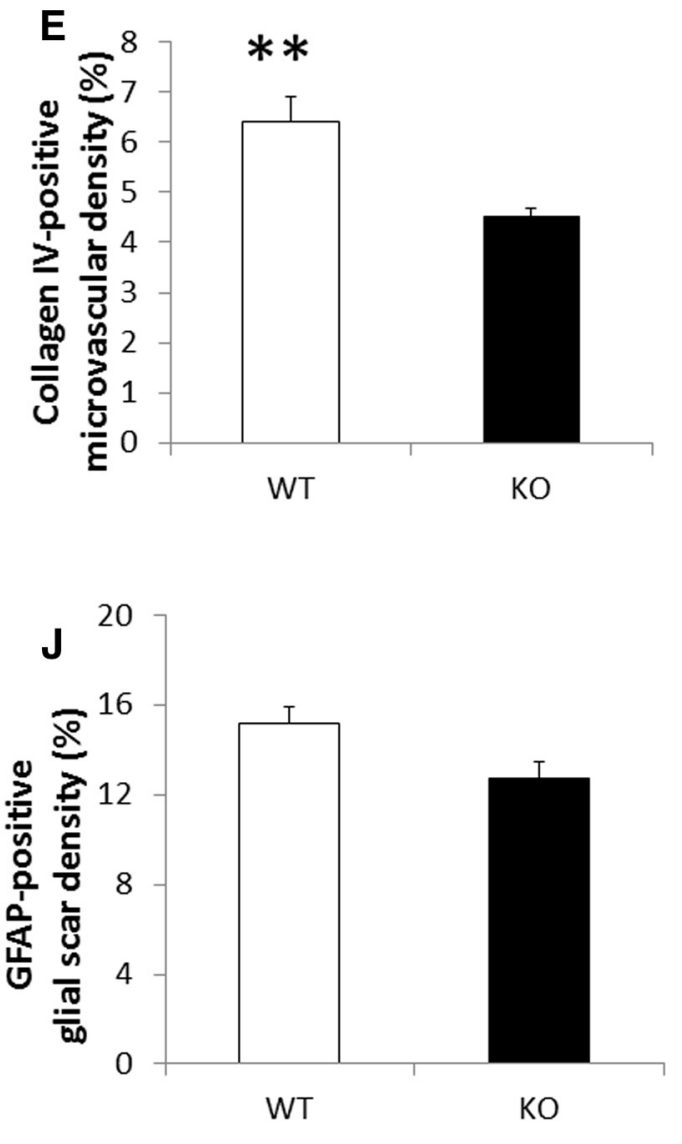

Figure 10. Angiogenesis but not glial scarring was decreased in TREM2-deficient mice. $\boldsymbol{A}-\boldsymbol{D}$, Angiogenesis after $14 \mathrm{~d}$ postischemia was evaluated in WT $(\boldsymbol{A}, \boldsymbol{C})$ and TREM2-deficient (K0; $\boldsymbol{B}, \boldsymbol{D})$ mice by collagen IV staining. $\boldsymbol{E}$, The fluorescence images show that collagen IV-positive parenchymal microvessels were significantly increased in the WT group compared with the KO group within the infarct border. Glial scarring and reactivity at the infarct border were also examined. $\boldsymbol{F}-\boldsymbol{J}$, Areas of GFAP positivity were slightly decreased in the K0 group $(\boldsymbol{G}, \boldsymbol{I})$ compared with the WT group $(\boldsymbol{F}, \boldsymbol{H})$, but this was not significantly different (J; NS). Scale bar, $100 \mu \mathrm{m} .{ }^{* *} p<0.01, n=8 /$ group.

reporter cells, which express lacZ under the NFAT promoter, were generated to overexpress TREM2 and DAP12, as previously described (Charles et al., 2008; Hsieh et al., 2009). Binding and activation of TREM 2 signaling was monitored by $\beta$-galactosidase expression. Neuro 2A cells were exposed to OGD, and conditioned media, cell extracts from the cytosol, mitochondria, nuclei, as well as purified DNA were cultured with the BWZ reporter cells as well as unmodified BWZ cells as controls. BWZ cells not receiving any samples, but left in their original media, were used as "untreated" controls. Conditioned media, as well as cell lysates from the nuclear and mitochondrial fractions, led to increased TREM2 signaling on the reporter cell line compared with unmodified BWZ cells, whereas conditioned media from cells not exposed to OGD as well as samples from the cytosol failed to elicit TREM2 signaling (Fig. 11B). These results suggest that nucleic acids are capable of eliciting TREM2 signaling.

\section{Discussion}

In this study, we provide several pieces of evidence to support the hypothesis that (1) microglial TREM2 is highly involved in the phagocytic activity following experimental stroke and is important in neurological recovery; and (2) a potential endogenous ligand for TREM2 might be extracellular nucleic acids.

Previous work identified microglia as the major brain cells expressing the highest levels of TREM2, (Schmid et al., 2002; Sessa et al., 2004), and TREM2 mediates microglial phagocytosis of apoptotic neurons in various neurological diseases (Takahashi et al., 2007; Hsieh et al., 2009; Neumann et al., 2009). Phagocytosis of apoptotic cells appear to be dependent upon microglial TREM2. Whether microglia play a beneficial or detrimental role in brain diseases has not been fully elucidated, but likely carry out both roles, depending on the nature and timing of the insult. Several recent reports (Wang et al., 2007; Iadecola and Anrather, 2011) have focused on the detrimental effects of microglia in acute brain injuries such as stroke, but there is clearly a balance between the damaging and beneficial properties. A recent report (Hu et al., 2012) showed that early after stroke, microglia and macrophages assume an anti-inflammatory, beneficial M2 phenotype, but transform into a proinflammatory detrimental M1 phenotype. Whether and how TREM2 participates in this phenotype switch is unknown, but it clearly seems to be involved in tissue recovery, as shown here. Several reports (Stoll et al., 2004; Schilling et al., 2005; Ito et al., 2007; Sierra et al., 2010) have shown that efficient clearance of tissue debris is critical in the reconstruction and reorganization of neuronal networks after injury. Schilling et al. (2005) demonstrated that both microglia and macrophages made contributions to debris clearance, including as cleavage of injured neurons. Phagocytosis of damaged cells have been also shown in many other diseases, such as Alzheimer's disease, trauma, Parkinson's disease, and amyotrophic lateral sclerosis (Fu et al., 2014). TREM2 gene variants have been linked to an increased risk of the development of Alzheimer's 


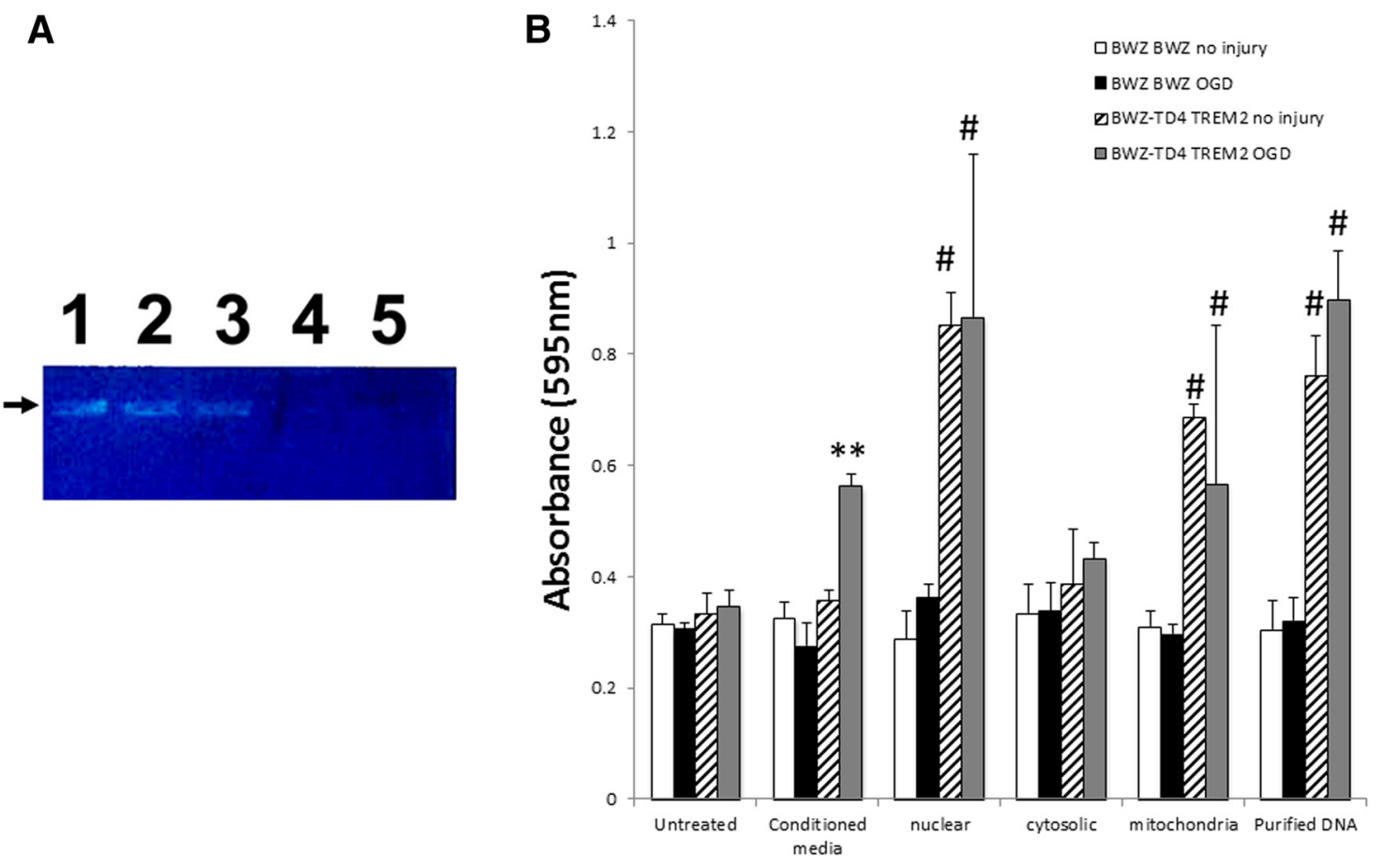

Figure 11. Nucleic acids as a potential TREM2 ligand in ischemic brain. $\boldsymbol{A}$, To identify potential ligands for TREM2 in ischemic brain, wild-type animals were subjected to experimental stroke and brains were probed with the TREM2 fusion protein to isolate potential binding partners. Since extracellular nucleic acids have been identified as ligands for other innate immune receptors, a modified ChIP assay was performed on fusion protein-probed lysates to delineate nucleic acids (SYBR green). Supernatant and pellet fractions were obtained from both ipsilateral and contralateral hemispheres $7 \mathrm{~d}$ post-dMCAO. A high-molecular-weight nucleic acid band was found to interact with the TREM2 fusion as shown in the agarose gel (arrow). Within ischemic brain, this highmolecular-weight band was observed in the supernatant as well as the pellet, whereas the band was only observed in the pellet fraction of the contralateral nonischemic hemisphere (lanes 1 and 3, pellet and supernatant of the ischemic hemisphere, respectively; lanes 2 and 4, pellet and supernatant of the contralateral hemisphere, respectively; lane 5, anti-human lgG control). B, A BWZ reporter cell line was used to assay TREM2 signaling in vitro. The BWZ lymphocyte cell line were modified to overexpress TREM2 linked to DAP12, NFAT, and and lacZ (BWZ-TD4 TREM2). In the presence of TREM2 ligand binding, activation can be assayed via $\beta$-gal expression. Neuro-2a cells were exposed to OGD, and lysates or conditioned media were applied to the reporter cells. Unmodified BWZ cells (BWZBWZ) were used as negative controls. Untreated reporter and control BWZ cells were also used as negative controls. Conditioned media from 0GD-exposed Neuro-2a cells led to increased TREM2 signaling, as evidenced by increased $\beta$-gal absorbance, compared with control media and media from uninjured Neuro-2a cells. To further suggest that nucleic acids may be responsible for TREM2 signaling, subcellular fractions were also applied to the BWZ control and reporter cells. Only fractions expected to contain nucleic acids led to increased signaling (nuclear, mitochondrial, and purified DNA), whereas fractions normally lacking nucleic acids (cytosolic) failed to signal. ${ }^{* *} p<0.001$ vs no injury; \#p $<0.001$ vs control BWZ cells.

disease (Jonsson et al., 2013). Further, genetic disruptions of TREM2 or its adapter protein DAP12 has been associated with a degenerative brain disease [Nasu-Hakola disease (or PLOSL)]. This rare disorder causes dementia, seizures, and death (Bianchin et al., 2004), supporting the notion that TREM2 is necessary for the maintenance of normal brain function. Autopsy studies of patients with this disorder revealed a sclerosing leukoencephalopathy with widespread microglial activation and microvascular angiopathy (Paloneva et al., 2001). TREM2 also appears to signal through anti-inflammatory pathways, and its deficiency leads to uncontrolled inflammation in a model of experimental autoimmune encephalomyelitis (EAE; Piccio et al., 2007).

In this study, we found that phagocytosis of injured brain was mostly abolished in the $\mathrm{KO}$ group, and infarct size was significantly larger in the $\mathrm{KO}$ animals. However, using a similar animal model, Sieber et al. (2013) failed to find differences in infarct size between TREM2 KO and WT animals subjected to experimental stroke. The reason for this difference remains unclear, but in their study, they applied 30 min MCA occlusion followed by reperfusion, compared with the current study, which applied permanent dMCAO. One possibility is that their study led to more infiltration of blood-borne immune cells during reperfusion compared with permanent MCAO, where fewer circulating immune cells have access to the ischemic brain. It is possible that macrophages in the brain in our model may have been more microglia predominant, whereas circulating macrophages that infiltrated the brain may have predominated in the study by Sieber et al. (2013). A prior report (Schilling et al., 2005) suggested that the phagocytic activity of brain microglia is more robust than the phagocytic activity of blood-borne macrophages. Interestingly, both studies reported a reduction in proinflammatory responses in the setting of TREM2 deficiency, and this is in contrast to what may have been predicted given the anti-inflammatory properties previously ascribed to TREM2.

Microglial phagocytosis relies on specific receptors expressed on the cell surface and downstream signaling pathways that contribute to the reorganization and engulfment of harmful microparticles (Fu et al., 2014). Different types of receptors on microglia have been shown to initiate and participate in phagocytosis (Aderem and Underhill, 1999). TLRs have been more widely studied and constitute a family of innate immune receptors that are generally known to initiate proinflammatory signaling. Their inhibition or deficiency has largely been shown to be anti-inflammatory and neuroprotective (Shichita et al., 2012). The TREM family of receptors, named because they have been detected exclusively on myeloid cells, has also been implicated in innate immune responses. TREM1 is known to trigger proinflammatory signals, while TREM2 leads to upregulation of antiinflammatory signals. A few reports (Takahashi et al., 2005; Hsieh et al., 2009) in noninfectious conditions have shown that TREM2 led to phagocytosis of apoptotic neurons. Our findings here suggest that this function of TREM2, that is, the clearing of damaged 
cells, may be important in setting the stage for eventual neurological recovery.

While the first recognized ligands for TREM2 included anionic molecules on bacteria and yeast, TREM2 was also found to bind an as yet unknown ligand in the brain (Daws et al., 2003). Despite substantial effort in searching for endogenous ligands of TREM2 by several investigators, it has yet to be fully identified. One prior report suggested the $60 \mathrm{kDa}$ heat shock protein (HSP60; Stefano et al., 2009); however, we were unable to show TREM2 activation when microglial BV2 cells were stimulated with HSP60 (data not shown), and HSP60 did not colocalize with the TREM2 in a model of experimental stroke (Kawabori et al., 2013 b). Further, the expression pattern of HSP60 did not parallel that of TREM2 in a model of therapeutic hypothermia in stroke. Here, we report that nucleic acids may be a potential TREM2 ligand in our ischemia model. We show that the TREM2 fusion protein associates with high-molecular-weight nucleic acids in ischemic brain, and OGD-exposed neurons elaborate a substance capable of eliciting TREM2 signaling. Further support of nucleic acids as a potential TREM2 ligand is that subcellular components likely to contain DNA or RNA (nuclear, mitochondrial) and purified DNA itself were similarly capable of causing TREM2 signaling using our reporter cell line. One possible scenario is that ischemia-injured brain cells lyse and release nucleic acids into the extracellular space, which can then bind TREM2 on neighboring microglia. This is not completely surprising, since nucleic acids are also known to bind and signal through TLRs and other innate immune receptors such as the purinergic receptors. The precise nucleic acids/nucleic acid sequences are unknown, but could be related to other previously identified danger-associated molecular patterns. More work is clearly needed in this area and should be the topic of future investigations.

In this study, we found that phagocytes deficient in TREM2 do not engulf apoptotic/necrotic cells, and this appears to impair the resorption of ischemic tissue. This is associated with worsened neurological recovery. However, TREM2 expression did not peak until $7 \mathrm{~d}$ after stroke, and yet, we saw improved neurological function as early as $1 \mathrm{~d}$. While this could be explained by even lower levels of TREM2 in the brain performing phagocytic functions, it is also possible that TREM2 may be carrying out activities in addition to clearing dead cells. Neumann et al. (2008) reported that microglia phagocytose infiltrating neutrophils, and neutrophils are known to elaborate proinflammatory molecules and worsen outcome in ischemic stroke. Thus, TREM2 may be important in limiting the acute proinflammatory state after stroke. TREM2 is also thought to elaborate anti-inflammatory immune molecules, and TREM2 deficiency has been associated with uncontrolled proinflammatory responses (Takahashi et al., 2005). Thus, some of the worsened outcomes in the TREM2 KO animals could be explained by exacerbated poststroke inflammation. However, we observed decreased microglial activation in our model, and Sieber et al. (2013) documented decreases in several proinflammatory cytokines and chemokines in the TREM2 KO brains. Thus, it is possible that the beneficial, phagocytic activities of TREM2 may be active in the ischemic brain before its peak expression. Regardless, TREM2 as a promoter of phagocytosis does appear to play a role in recovery. Phagocytosis of necrotic debris is also thought to be necessary for axon regeneration (Fu et al., 2014), and intravenous administration of TREM2-rich stem cells facilitated brain repair in EAE (Takahashi et al., 2007).

We report for the first time that TREM2 plays a role in the phagocytosis of the ischemically injured brain cells and is involved in neurological recovery. We suggest that TREM2 should be studied further in stroke and related brain injuries, and in neurodegenerative diseases. Its deficiency or genetic variants can lead to worsened outcome or increase disease risk.

\section{References}

Aderem A, Underhill DM (1999) Mechanisms of phagocytosis in macrophages. Annu Rev Immunol 17:593-623. CrossRef Medline

Bianchin MM, Capella HM, Chaves DL, Steindel M, Grisard EC, Ganev GG, da Silva Júnior JP, Neto Evaldo S, Poffo MA, Walz R, Carlotti Júnior CG, Sakamoto AC (2004) Nasu-Hakola disease (polycystic lipomembranous osteodysplasia with sclerosing leukoencephalopathy-PLOSL): a dementia associated with bone cystic lesions. From clinical to genetic and molecular aspects. Cell Mol Neurobiol 24:1-24. CrossRef Medline

Charles JF, Humphrey MB, Zhao X, Quarles E, Nakamura MC, Aderem A, Seaman WE, Smith KD (2008) The innate immune response to Salmonella enterica serovar Typhimurium by macrophages is dependent on TREM2-DAP12. Infect Immun 76:2439-2447. CrossRef Medline

Colonna M (2003) TREMs in the immune system and beyond. Nat Rev Immunol 3:445-453. CrossRef Medline

Daws MR, Lanier LL, Seaman WE, Ryan JC (2001) Cloning and characterization of a novel mouse myeloid DAP12-associated receptor family. Eur J Immunol 31:783-791. CrossRef Medline

Daws MR, Sullam PM, Niemi EC, Chen TT, Tchao NK, Seaman WE (2003) Pattern recognition by TREM-2: binding of anionic ligands. J Immunol 171:594-599. CrossRef Medline

del Zoppo GJ, Frankowski H, Gu YH, Osada T, Kanazawa M, Milner R, Wang X, Hosomi N, Mabuchi T, Koziol JA (2012) Microglial cell activation is a source of metalloproteinase generation during hemorrhagic transformation. J Cereb Blood Flow Metab 32:919-932. CrossRef Medline

Fu R, Shen Q, Xu P, Luo JJ, Tang Y (2014) Phagocytosis of microglia in the central nervous system diseases. Mol Neurobiol 49:1422-1434. CrossRef Medline

Guerreiro R, Hardy J (2013) TREM2 and neurodegenerative disease. N Engl J Med 369:1569-1570. Medline

Hsieh CL, Koike M, Spusta SC, Niemi EC, Yenari M, Nakamura MC, Seaman WE (2009) A role for TREM2 ligands in the phagocytosis of apoptotic neuronal cells by microglia. J Neurochem 109:1144-1156. CrossRef Medline

Hu X, Li P, Guo Y, Wang H, Leak RK, Chen S, Gao Y, Chen J (2012) Microglia/macrophage polarization dynamics reveal novel mechanism of injury expansion after focal cerebral ischemia. Stroke 43:3063-3070. CrossRef Medline

Iadecola C, Anrather J (2011) The immunology of stroke: from mechanisms to translation. Nat Med 17:796-808. CrossRef Medline

Ito M, Kuroda S, Sugiyama T, Maruichi K, Kawabori M, Nakayama N, Houkin K, Iwasaki Y (2012) Transplanted bone marrow stromal cells protect neurovascular units and ameliorate brain damage in stroke-prone spontaneously hypertensive rats. Neuropathology 32:522-533. CrossRef Medline

Ito U, Nagasao J, Kawakami E, Oyanagi K (2007) Fate of disseminated dead neurons in the cortical ischemic penumbra: ultrastructure indicating a novel scavenger mechanism of microglia and astrocytes. Stroke 38:25772583. CrossRef Medline

Jonsson T, Stefansson H, Steinberg S, Jonsdottir I, Jonsson PV, Snaedal J, Bjornsson S, Huttenlocher J, Levey AI, Lah JJ, Rujescu D, Hampel H, Giegling I, Andreassen OA, Engedal K, Ulstein I, Djurovic S, IbrahimVerbaas C, Hofman A, Ikram MA, et al (2013) Variant of TREM2 associated with the risk of Alzheimer's disease. N Engl J Med 368:107-116. CrossRef Medline

Kacimi R, Giffard RG, Yenari MA (2011) Endotoxin-activated microglia injure brain derived endothelial cells via NF-kappaB, JAK-STAT and JNK stress kinase pathways. J Inflamm (Lond) 8:7. CrossRef Medline

Kauppinen TM, Swanson RA (2005) Poly(ADP-ribose) polymerase-1 promotes microglial activation, proliferation, and matrix metalloproteinase9-mediated neuron death. J Immunol 174:2288-2296. CrossRef Medline Kauppinen TM, Suh SW, Higashi Y, Berman AE, Escartin C, Won SJ, Wang C, Cho SH, Gan L, Swanson RA (2011) Poly(ADP-ribose)polymerase-1 modulates microglial responses to amyloid beta. J Neuroinflammation 8:152. CrossRef Medline

Kawabori M, Kuroda S, Sugiyama T, Ito M, Shichinohe H, Houkin K, Kuge Y, Tamaki N (2012) Intracerebral, but not intravenous, transplantation of bone marrow stromal cells enhances functional recovery in rat cerebral 
infarct: an optical imaging study. Neuropathology 32:217-226. CrossRef Medline

Kawabori M, Kuroda S, Ito M, Shichinohe H, Houkin K, Kuge Y, Tamaki N (2013a) Timing and cell dose determine therapeutic effects of bone marrow stromal cell transplantation in rat model of cerebral infarct. Neuropathology 33:140-148. CrossRef Medline

Kawabori M, Hokari M, Zheng Z, Kim JY, Calosing C, Hsieh CL, Nakamura MC, Yenari MA (2013b) Triggering receptor expressed on myeloid cells-2 correlates to hypothermic neuroprotection in ischemic stroke. Ther Hypothermia Temp Manag 3:189-198. CrossRef Medline

Kawase M, Murakami K, Fujimura M, Morita-Fujimura Y, Gasche Y, Kondo T, Scott RW, Chan PH (1999) Exacerbation of delayed cell injury after transient global ischemia in mutant mice with CuZn superoxide dismutase deficiency. Stroke 30:1962-1968. CrossRef Medline

Lee JE, Yenari MA, Sun GH, Xu L, Emond MR, Cheng D, Steinberg GK, Giffard RG (2001) Differential neuroprotection from human heat shock protein 70 overexpression in in vitro and in vivo models of ischemia and ischemia-like conditions. Exp Neurol 170:129-139. CrossRef Medline

Neumann H, Kotter MR, Franklin RJ (2009) Debris clearance by microglia: an essential link between degeneration and regeneration. Brain 132:288295. CrossRef Medline

Neumann J, Sauerzweig S, Rönicke R, Gunzer F, Dinkel K, Ullrich O, Gunzer M, Reymann KG (2008) Microglia cells protect neurons by direct engulfment of invading neutrophil granulocytes: a new mechanism of CNS immune privilege. J Neurosci 28:5965-5975. CrossRef Medline

Numasawa Y, Yamaura C, Ishihara S, Shintani S, Yamazaki M, Tabunoki H, Satoh JI (2011) Nasu-Hakola disease with a splicing mutation of TREM2 in a Japanese family. Eur J Neurol 18:1179-1183. CrossRef Medline

Paloneva J, Autti T, Raininko R, Partanen J, Salonen O, Puranen M, Hakola P, Haltia M (2001) CNS manifestations of Nasu-Hakola disease: a frontal dementia with bone cysts. Neurology 56:1552-1558. CrossRef Medline

Piccio L, Buonsanti C, Mariani M, Cella M, Gilfillan S, Cross AH, Colonna M, Panina-Bordignon P (2007) Blockade of TREM-2 exacerbates experimental autoimmune encephalomyelitis. Eur J Immunol 37:1290-1301. CrossRef Medline

Sanderson S, Shastri N (1994) LacZ inducible, antigen/MHC-specific T cell hybrids. Int Immunol 6:369-376. CrossRef Medline

Schilling M, Besselmann M, Müller M, Strecker JK, Ringelstein EB, Kiefer R (2005) Predominant phagocytic activity of resident microglia over hematogenous macrophages following transient focal cerebral ischemia: an investigation using green fluorescent protein transgenic bone marrow chimeric mice. Exp Neurol 196:290-297. CrossRef Medline

Schmid CD, Sautkulis LN, Danielson PE, Cooper J, Hasel KW, Hilbush BS, Sutcliffe JG, Carson MJ (2002) Heterogeneous expression of the triggering receptor expressed on myeloid cells- 2 on adult murine microglia. J Neurochem 83:1309-1320. CrossRef Medline

Sessa G, Podini P, Mariani M, Meroni A, Spreafico R, Sinigaglia F, Colonna M, Panina P, Meldolesi J (2004) Distribution and signaling of TREM2/ DAP12, the receptor system mutated in human polycystic lipomembra- neous osteodysplasia with sclerosing leukoencephalopathy dementia. Eur J Neurosci 20:2617-2628. CrossRef Medline

Shichita T, Ago T, Kamouchi M, Kitazono T, Yoshimura A, Ooboshi H (2012) Novel therapeutic strategies targeting innate immune responses and early inflammation after stroke. J Neurochem 123 [Suppl 2]:29-38. CrossRef Medline

Sieber MW, Jaenisch N, Brehm M, Guenther M, Linnartz-Gerlach B, Neumann H, Witte OW, Frahm C (2013) Attenuated inflammatory response in triggering receptor expressed on myeloid cells 2 (TREM2) knock-out mice following stroke. PLoS One 8:e52982. CrossRef Medline

Sierra A, Encinas JM, Deudero JJ, Chancey JH, Enikolopov G, OverstreetWadiche LS, Tsirka SE, Maletic-Savatic M (2010) Microglia shape adult hippocampal neurogenesis through apoptosis-coupled phagocytosis. Cell Stem Cell 7:483-495. CrossRef Medline

Stefano L, Racchetti G, Bianco F, Passini N, Gupta RS, Panina Bordignon P, Meldolesi J (2009) The surface-exposed chaperone, Hsp60, is an agonist of the microglial TREM2 receptor. J Neurochem 110:284-294. CrossRef Medline

Stoll G, Schroeter M, Jander S, Siebert H, Wollrath A, Kleinschnitz C, Brück W (2004) Lesion-associated expression of transforming growth factorbeta-2 in the rat nervous system: evidence for down-regulating the phagocytic activity of microglia and macrophages. Brain Pathol 14:51-58. CrossRef Medline

Takahashi K, Rochford CD, Neumann H (2005) Clearance of apoptotic neurons without inflammation by microglial triggering receptor expressed on myeloid cells-2. J Exp Med 201:647-657. CrossRef Medline

Takahashi K, Prinz M, Stagi M, Chechneva O, Neumann H (2007) TREM2transduced myeloid precursors mediate nervous tissue debris clearance and facilitate recovery in an animal model of multiple sclerosis. PLoS Med 4:e124. CrossRef Medline

Tang XN, Wang Q, Koike MA, Cheng D, Goris ML, Blankenberg FG, Yenari MA (2007) Monitoring the protective effects of minocycline treatment with radiolabeled annexin $\mathrm{V}$ in an experimental model of focal cerebral ischemia. J Nucl Med 48:1822-1828. CrossRef Medline

Tang XN, Zheng Z, Giffard RG, Yenari MA (2011) Significance of marrowderived nicotinamide adenine dinucleotide phosphate oxidase in experimental ischemic stroke. Ann Neurol 70:606-615. CrossRef Medline

Wang Q, Tang XN, Yenari MA (2007) The inflammatory response in stroke. J Neuroimmunol 184:53-68. CrossRef Medline

Webster CM, Hokari M, McManus A, Tang XN, Ma H, Kacimi R, Yenari MA (2013) Microglial P2Y12 deficiency/inhibition protects against brain ischemia. PLoS One 8:e70927. CrossRef Medline

Yenari MA, Xu L, Tang XN, Qiao Y, Giffard RG (2006) Microglia potentiate damage to blood-brain barrier constituents: improvement by minocycline in vivo and in vitro. Stroke 37:1087-1093. CrossRef Medline

Yenari MA, Kauppinen TM, Swanson RA (2010) Microglial activation in stroke: therapeutic targets. Neurotherapeutics 7:378-391. CrossRef Medline

Zheng Z, Kim JY, Ma H, Lee JE, Yenari MA (2008) Anti-inflammatory effects of the $70 \mathrm{kDa}$ heat shock protein in experimental stroke. J Cereb Blood Flow Metab 28:53-63. CrossRef Medline 